\title{
Current research and emerging tools to improve fresh red meat quality
}

M. Gagaoua ${ }^{1 \dagger}$, G. Duffy², C. Alvarez¹, C.M. Burgess², R. Hamill'1, E. Crofton¹, C. Botinestean ${ }^{3}$, A. Ferragina ${ }^{1}$, J. Cafferky ${ }^{1}$, A.M. Mullen ${ }^{1}$ and D. Troy ${ }^{4}$

${ }^{1}$ Food Quality and Sensory Science Department, Teagasc Food Research Centre, Ashtown, D15 KN3K Dublin, Ireland

${ }^{2}$ Food Safety Department, Teagasc Food Research Centre, Ashtown, D15 KN3K Dublin, Ireland

${ }^{3}$ Food Industry Development Department, Teagasc Food Research Centre, Ashtown, D15 KN3K Dublin, Ireland

${ }^{4}$ Teagasc Food Research Centre, Ashtown, D15 KN3K Dublin, Ireland

Abstract

A consumer's decision to purchase red meat is guided by a combination of many interacting factors including safety, nutrition, sustainability and perception of healthiness along with a variety of sensory characteristics such as colour, marbling, tenderness, juiciness and flavour. Red meat quality is complex and influenced by many intrinsic and extrinsic factors, spanning the chain from breed/genetics through to the final end product with key influences coming from on-farm management and post-mortem processing. As a result of various factors, including consumer demands, the importance of both red meat quality and safety has in recent times come to the fore for the meat industry, with steps to meet these requirements having a large bearing on profitability. Therefore, a critical review of steps which can help control these traits is very important. Accordingly, several processing strategies were proposed at the research and industry level aiming to improve fresh red meat quality traits. This review summarises the current methods applied to improve fresh red meat quality and safety, including the advances in management and prediction tools for carcass and technological and sensory quality traits. These methods are also relevant to the safety and microbiological status of carcasses and meat produced, along with the recent developments in sensory analysis, which aim to understand the sensory properties of red meat and consumers responses. The potential of foodomics approaches is discussed under the topics of genomics, proteomics and metabolomics, which help our understanding of the underlying biological mechanisms behind the variation of sensory and technological quality traits and their use for the discovery of putative biomarkers. We further considered the current and emerging sequencing-based methods used to understand microbial community composition of fresh red meat.

Keywords

Biomarkers $•$ foodomics $•$ meat and carcass quality management $\bullet$ meat quality evaluation $\bullet$ prediction tools $\bullet$ safety and

microbiology of fresh red meat $\bullet$ sensory science

\section{Introduction}

Meat quality can be defined in many ways, but for the consumer, safety and sensory quality represent key criteria. These attributes are complex and are influenced by a multitude of both intrinsic and extrinsic interacting factors. These include, for example, genetics, production systems, feed, pre-mortem animal handling and stress at slaughter, post-mortem carcass handling, technological treatments and their interactions (Moloney et al., 2001; Troy \& Kerry, 2010; Hocquette et al., 2012; Gagaoua \& Picard, 2020; Terlouw et al., 2021). Consumer demands for high-quality, safe, nutritious and healthier red meat products have recently provided an impetus into the development of several innovative and non-destructive methods, sensory protocols and decision tools aiming to evaluate, control and improve the quality or to deepen our understanding of biological mechanisms underpinning the variation in technological and sensory quality traits of red meat. For economic considerations and consumers' satisfaction, red meat quality also constitutes an important concern for industry stakeholders who continually seek innovative and sustainable approaches to improve all the aspects of red meat quality.

This review, based on recent literature but not considering production systems or animal management, is organised into three main sections focusing on the current advances 
and emerging methods used to control and improve the sensory quality and safety of fresh red meat products (mainly beef and lamb). The first section discusses recent advances and the potential of foodomics (genomics, proteomics and metabolomics), rapid and non-destructive physical and imaging methods to improve and predict red meat quality as well as the emerging post-mortem intervention methods used to increase meat tenderness, mainly in beef. The second section focuses on the safety aspects of fresh red meat by describing the current interventions used to control microorganisms in the meat chain, the methods of characterisation and the potential of powerful sequence-based methods such as whole-genome sequencing, metagenomics and meta-transcriptomics to tackle the comprehensive assessment of red meat safety to ensure the health of consumers in a globalised market. Finally, the last section covers the recent advances in sensory analysis relevant to fresh red meat.

\section{Recent advances in the management and prediction of technological and sensory quality traits of fresh red meat}

\section{Foodomics as a tool towards understanding variation in,} and predicting, meat quality traits

During the last two decades, new OMICs technologies, referred to in this context as foodomics, have been applied to widen the scope of traditional methods and open up impressive possibilities to explore the unknowns relevant to meat science and quality variation of fresh red meat and processed meat products (Herrero et al., 2012; Munekata et al., 2021; Purslow et al., 2021). Genomics, transcriptomics, proteomics, metabolomics and so on combined with chemometrics methods were further used to predict the potential quality of red meat quality traits (Gagaoua et al., 2020a).

\section{Livestock genomics and red meat quality}

While natural variability in the genomic DNA sequence includes insertions, deletions, inversions and copy number variations of 10 s to 1000 s of bases, which can all contribute to variation in a trait of interest, DNA single-nucleotide polymorphisms (SNPs) are the most common type of genetic variation in the genome. Agrigenomics resources arising from genome sequencing projects include DNA chips containing thousands to hundreds of thousands of SNPs evenly spaced throughout the genome (Ghosh et al., 2018). The ability to analyse genetic diversity in the population has been further expanded through important projects such as 1000 Bull Genomes, which involves whole-genome sequencing of pedigree bulls, facilitating the expansion of information that can be collected from these chips about the population, to levels way beyond the size of the chip, and even up to the whole genome level, through imputation (Hayes \& Daetwyler, 2019). While these chips are used to drive genomic selection, which accelerates the pace of genetic improvement in livestock due to early availability of the predicted breeding value of calves (Meuwissen et al., 2016), they can also be used to identify the genomic regions associated with a trait in the population. Important initiatives relate to genome annotation and the need for standardisation of methods, ontologies and a common infrastructure for data sharing and acceleration of annotation such as the Functional Annotation of Farm Animal Genomes project (FAANG, https:// www.faang.org/) and a common resource for the repository of information on gene regions associated with important livestock traits (Animal QTLdb, https://www.animalgenome. org/QTLdb/).

Although next-generation sequencing (NGS) has resulted in huge progress in livestock genomics, read depths are variable and substantial gaps remain in genomes (Taylor et al., 2016). Current technological developments include the advent of third-generation (long read Nanopore and PacBio) sequencing approaches. Although not as accurate as short read sequencing, they seemed to be fast and sequencing reads are long (10-60 kb), hence they are leading to progress with livestock genome projects at the forefront, for example, goat (Bickhart et al., 2017) and water buffalo (Low et al., 2019) genome builds which each surpassed the human genome in contiguity. These technologies have high relevance in microbiome and pathogen sequencing and the Nanopore MinION technology has the capability to bring genome sequencing at the slaughterhouse level and to countries with more limited infrastructure for genome sequencing (Lamb et al., 2020).

Genetic regions and gene expression associated with meat quality

Meat quality traits are moderately heritable with recent heritability estimates ranging from $\sim 0.1$ to 0.2 for sensory traits such as tenderness, juiciness, flavour and chewiness (Berry et al., 2021). Single-nucleotide polymorphisms variants that are causative and impact on the phenotype, depending on their location in the genome, exert their effects on a given trait via different mechanisms. These include changing the amino acid sequence of the synthesised protein or activating enhancing or suppressing the level of expression of a gene. The causative variants are in linkage disequilibrium with neighbouring SNPs, hence SNP chips can be used to map the trait to quantitative trait loci (QTLs) (Hu et al., 2018). At present, 19 sensory-related traits (including Warner-Bratzler shear force [WBSF]) are included in AnimalQTLdb with 759 QTL for these traits across all 30 chromosomes with notable representation on chromosomes $3,7,10,18,21-23$ and 29, for which several biomarkers of beef tenderness and colour were confirmed (Gagaoua et al., 2020b, 2021b). Some genes 
such as myostatin (GDF8) and insulin-like growth factor 2 (IGF2) harbour variants that cause major effects in livestock species, and they are master regulators in muscle growth and development (Van Laere et al., 2003; Aiello et al., 2018). These genes are robustly associated with muscle characteristics in diverse bovine breeds, although the DNA variation may differ per breed. For other genes, such as calpains, the regions harbouring these genes are also consistently significant in a range of genome-wide association studies (GWAS), though conclusive identification of causative mutations remains elusive (Aiello et al., 2018). Calpains represent an important family of proteolytic enzymes, with $\mu$-calpain (CAPN1) involved in post-mortem tenderisation of meat, while calpastatin, its inhibitor, and the SNP in these genes have long been known to be associated with tenderness (Page et al., 2002; Casas et al., 2006).

It is widely considered that tenderness is the most important trait relating to palatability in meat quality, namely beef (Gagaoua et al., 2019a). However, recent studies have shown that once variation in beef tenderness is controlled, flavour becomes the most important driver of eating acceptability (Killinger et al., 2004; O'Quinn et al., 2018). The past 5 yr have seen numerous genome-wide association and transcriptomic sequencing studies, as well as the advent of new methods for targeted monitoring of gene expression profiles from specific pathways and candidate genes (Aiello et al., 2018). A genomewide analysis for an instrumental measure of beef tenderness, WBSF, conducted in five Bos taurus breeds revealed 79 QTLs associated with WBSF in at least one breed, with 37 QTLs identified in at least four of the five breeds, indicating a strong association with WBSF (McClure et al., 2012). Candidate genes present within the 37 QTLs, shared by four breeds, include $\mu$-calpain and calpastatin on bovine chromosomes BTA7 and BTA29, respectively (McClure et al., 2012). Other candidate genes proposed by the authors include MYOD1 located on BTA15 which is expressed in muscle during growth and regeneration, fibroblast growth factor 2 (FGF2) regulating heat shock proteins on BTA17, gelsolin (GSN) on BTA8 and calmodulin (CALM1) on BTA10. A study on both Bos indicus and Bos taurus breeds which included a separate validation test population confirmed the QTLs for WBSF on BTA7 (Bolormaa et al., 2011). Recent studies on Simmental breed using HD chips (>777k SNPs) are also confirmatory of the QTL on BTA7 for shear force (Xia et al., 2016).

Progress in refining QTLs has been facilitated by recent developments, such as imputation of variants not present on the gene chips, which has led to the identification of 114 SNPs significant at the genome level and QTLs for marbling, meat colour, fat colour and texture in Hanwoo cattle (Bedhane et al., 2019). Several of the QTLs for beef colour were confirmed in proteomic studies that identified candidate protein biomarkers (Gagaoua et al., 2020b). On another hand, a recent study focused on Angus examined a range of traits, but their tenderness analysis not only confirmed the known QTLs including the calpain gene, but of the most significant structural genes highlighted in the study, $81 \%$ were validated using in silico analysis to be substrates of calpains (LealGutiérrez et al., 2020c), illustrating the central importance of this proteolytic process in defining ultimate beef tenderness. Furthermore, experimental validation of the functional relationship of putative candidate genes with their proposed phenotype is a very valuable addition to GWAS. S-myotrophin is a novel gene for that was discovered in a GWAS study using imputed sequences in Simmental cattle, and was subsequently demonstrated to play a role in promoting muscle hypertrophy and inhibiting differentiation (Bordbar et al., 2020).

Transcriptomic approaches have provided information on changes at the gene expression level which are associated with meat quality (Guo \& Dalrymple, 2017). A synthetic index combining shear force, sensory tenderness, connective tissue and marbling score was created in an Angus-Brahman population, and RNA sequencing (RNA-seq) was applied to the most divergent animals (Leal-Gutiérrez et al., 2020a). Cytoskeletal and transmembrane anchoring genes were over-represented (Leal-Gutiérrez et al., 2020a). From this study, the most significantly differentially expressed genes were novel (e.g. ARHGAP10 and ARRDC4), while others had previously been associated with meat quality in GWAS (e.g. KIAA2013). A follow-up expression OTL (eQTL) study of the same animals uncovered a number of predicted master regulator genes involved in muscle and meat quality. For example, neurotrophic factor 3 (NTF3), which plays a role in the regulation of myofibre and myoblast differentiation, has previously been associated with cooking loss (LealGutiérrez et al., 2020b). Of the 17 master regulators with specific functions, nine were membrane proteins, four were transcription factors, three were cytoskeletal proteins and one was a DNA methylase. Other noteworthy genes in the study included Titin and TEK (angiopoietin-1 receptor known also as a tyrosine-protein kinase), which appeared to be under substantial multigene regulation and also were located close to significant splicing cis-regulatory SNP. In another study, Fu et al. (2020) combined gene expression with GWAS and quantitative trait expression profiles to refine 180 candidate genes for fat-related traits down to just six, including known master regulators such as several PPARs (PPARG, PPARD and PPARA). New insights have been gained on the molecular pathways underpinning heterosis and its implications for growth, development and meat quality in sheep meat using RNA sequencing (Cheng et al., 2020). Allele-specific expression occurs where a single allele is expressed in a heterozygote and where this is driven by differential methylation due to parental effects, and it is termed imprinting. Many genes involved in growth and metabolism are indeed 
imprinted (O'Doherty et al., 2015). Recent studies examined allele-specific expression in the Bos indicus transcriptome, finding the phenomenon to be widespread, with imbalance in allelic expression of many genes known previously to be associated with meat quality such as the ryanodine receptor (RYR1), calsequestrin (CASQ1) in the same pathway (calcium homeostasis), myomesin (MYOM1) and myosin light chain 1 (MYL1) which interact with each other and are known as proteomic biomarkers of beef ageing (Gagaoua et al., 2021c), and ALDH5A1 involved in the pathway 4-aminobutanoate degradation, which is part of amino acid degradation that has previously been shown in a GWAS to be associated with tenderness, fat colour and water-holding capacity (de Souza et al., 2020; Bruscadin et al., 2021).

Future trends of genomics and transcriptomics in the field of red meat science

Even well-powered GWAS can lead to the identification of large genomic regions frequently containing hundreds of genes, and refining these regions down to putative candidate genes and ultimately quantitative trait variants for a trait is challenging. There is consensus around a need for the different types of OMIC approaches (e.g. genome/transcriptome/proteome/ metabolome) to be integrated together in a multi-omics approach (Da Silva Diniz \& Ward, 2021). Recent studies have taken such an approach to refining genomic regions and lists of potential candidate genes in pork (Welzenbach et al., 2016) and beef (Cardoso et al., 2021) and it is likely to grow in importance in future livestock studies.

While SNP variation can be profiled with SNP chips and modern sequencing methods, other types of variation such as copy number variation and variation in low complexity repetitive regions are more challenging to routinely score in populations, and they potentially account for a substantial proportion of the so-called "missing heritability" observed in many livestock genomic traits, that is, heritability not accounted for by common SNP variants. With long read sequencing, there is hope that these alternative types of common genetic variation could be properly characterised and shed more light on the molecular regulation of meat quality (Gonzalez-Recio et al., 2015).

When the causative genes and variants contributing to a trait are known, the future of agrigenomics is likely to include genome editing in a precise and targeted way and these approaches have been tested with successful introgression of a number of disease-resistant, welfare-related and muscling (myostatin) genetic variants in livestock (Tait-Burkard et al., 2018).

In the era of big data and data analytics, and in a time when genomic information is easier than ever to collect, an important limitation on fully elucidating genomic features of relevance relates to the "shape" of data that is commonly generated. Within genomic data sets, and OMICs data in general, the number of data points recorded for each sample is vastly greater than the number of samples/phenotypes in a typical study and this challenges statistical inference.

\section{Proteomics to study red meat quality and discover candidate} protein biomarkers

Faced with the recurrent and increasing demands for consistent and high-quality red meat, farmers and meat industry stakeholders have changed their production methods and modernised breeding practices, leading to improvements in the potential of breeds and adaptability of the animals, which has an impact on the quality and variability of the meat produced (Gagaoua \& Picard, 2020). Therefore, product quality prediction becomes an absolute necessity for the meat industry. In addition, meat quality assessment methods (whether sensory or mechanical) are considered destructive and not easy to implement routinely. In this sense, there is a need to find an alternative and to develop simple and fast decision tools that do not require large quantities of meat samples to classify and predict the potential quality from live animals, carcasses early post-mortem or cuts at the point of sale. Proteomics seemed to be an effective solution to this problem (Bendixen, 2013; Gagaoua et al., 2020a) through the global or partial study of the proteome (muscle tissue or fluids such as plasma) to propose explanatory mechanisms for the origin of the variability of red meat quality traits. Thus, a range of proteomics methods (gel-based and gel-free approaches coupled with mass spectrometry) have been applied to investigate important meat quality traits (Picard \& Gagaoua, 2017; Picard et al., 2017; López-Pedrouso et al., 2020) including tenderness (Gagaoua et al., 2020a; Picard \& Gagaoua, 2020; Gagaoua et al., 2021b; Zhu et al., 2021a, 2021b), colour (Nair et al., 2018a, 2018b; Gagaoua et al., 2020b), water-holding capacity (Di Luca et al., 2013, 2016; Tao et al., 2021), marbling (Ceciliani et al., 2018; Bazile et al., 2019) and pH decline (Gagaoua et al., 2015, 2021d; Poleti et al., 2018). In addition, proteomics was used to investigate the dynamic changes and modifications occurring in postmortem muscle proteome (Gagaoua et al., 2021c; Zhou et al., 2021).

The main research area where meat proteomics has been applied is in the field of protein biomarkers discovery (Picard \& Gagaoua, 2020). Generally, the first phase in the pipeline of biomarkers discovery focuses on identifying differential abundances in proteins in groups of samples (mainly muscle biopsies and recently other biological sources such as plasma are tested) which are distinctly divergent for a phenotype of interest, such as tenderness (Picard \& Gagaoua, 2020; Gagaoua et al., 2021b; Zhu et al., 2021b). It is important that conditions are standardised within the study, for example, muscle (e.g. M. longissimus thoracis), same animal type, same rearing conditions, same muscle preparation approach 
and so on, to analyse only the trait of interest. This first phase called "discovery" is composed of several steps from sampling and categorisation, protein extraction until the identification of the proteins of interest by mass spectrometry and their quantification. This strategy was extensively described by Picard \& Gagaoua (2020) in their integrative beef tenderness proteomics study, which considered separately several important factors such as muscle, breed, gender as well as the evaluation method of meat quality. In our quest for beef tenderness biomarkers, a recent ground-breaking integromics meta-analysis based on 28 proteomics studies from the literature enabled us to propose the first atlas of 124 biomarkers from which 64 were found in a minimum of two studies, allowing then to shortlist a robust panel of 33 beef tenderness biomarkers identified in at least four experiments for validation (Gagaoua et al., 2021b). Moreover, protein network analysis delivered a functional annotation of the 124 proteins from M. longissimus thoracis and provided key insights into the interconnectedness among various pathways and processes in the muscle, which are pivotal in producing high-quality beef. There were six interconnected pathways identified to play a pivotal role in the determination of beef tenderness. Those were (i) muscle contraction and structure development; ii) energy metabolism; (iii) cellular responses to stress; (iv) response to oxidative stress; (v) proteolysis and (vi) regulation of cellular processes, binding, apoptosis and transport. Similar integromics proteomics studies were further conducted to create biomarker repertoires for beef colour (Gagaoua et al., 2020b) and the quality defect of dark, firm and dry (DFD) beef, otherwise termed dark-cutting beef (Gagaoua et al., 2021d). The ultimate objective of biomarkers discovery is to propose a robust list of validated biomarkers that would allow development of routine bioanalytical tools that can be used by stakeholders for testing the potential quality of the carcasses in the slaughterhouse, their management early post-mortem as well as for breeders to improve the potential merits of breeds.

Emerging use of metabolomics in meat quality analysis and authentication

Metabolomics can be defined as the study and analysis of metabolite molecules that have a molecular weight lower than 1,000 $\mathrm{Da}$ (including free amino acids and short peptides, monosaccharides, organic acids, lipids, vitamins or nucleotides). Such metabolites can be affected by several factors in the food-processing chain and these will be reflected in the metabolome profiles including in meat and processed meat products (for review: Muroya et al., 2020). The profiles obtained for such low-molecular-weight compounds can be further correlated with sensory properties and functional and nutritional profiles, providing a deeper understanding of the factors affecting the final eating meat quality traits and the underlying mechanisms. This approach can further lead to the identification of potential biomarkers that can be used as indicators of those meat quality traits such as tenderness and flavour (Kodani et al., 2017; King et al., 2019).

The study by King et al. (2019) reported that a significant increase in the concentration of free amino acids (mainly methionine and tyrosine) was correlated with samples categorised as tender, and these values were higher as ageing time increased. A similar correlation was found for two glycolysis metabolites, namely glucose and glucose-6phosphate. On the other hand, glycerol-3-phosphate and 3-phosphoglyceric acid were observed to be significantly more concentrated in tough beef. Similar findings were reported when Japanese Black cattle was investigated over a period of 10 wk of ageing (Kodani et al., 2017). In fact, increasing amounts of free amino acids (Leu, lle, Val and Ala) as well as acetic acid were detected. These studies revealed that nuclear magnetic resonance (NMR)-based metabolomics, for instance, has the potential to evaluate multiple parameters related to beef qualities. In another study, Ma et al. (2017) reported that an increased amount of free amino acids is related to the extent of proteolysis, which is indicative of more tender meat, but also it is related to more precursors of aromatic compounds that play a role in the sensory perception of cooked meat. These authors further correlated the concentrations of nicotinamide adenine dinucleotide (NADH) and its oxidised form NAD+ with the oxidative status of the meat, and its direct correlation with colour stability which deteriorated as these compounds were depleted by extended ageing. The relevance of carnitine, creatine and carnosine, as candidate metabolic biomarkers of meat quality (beef, lamb and yak), has been proposed (Jeong et al., 2020; Zhu et al., 2020; Wang et al., 2021). Such compounds have a relevant role in the muscle metabolism, associated mainly with oxidative pathways and lipid transformation into metabolic energy. Antonelo et al. (2020) reported a positive correlation between carnosine and consumer acceptance of beef steaks, while carnitine and creatine were strongly negatively correlated with consumer sensory traits (overall liking, tenderness and juiciness scores).

In light of these studies, it is important to note that the potential of metabolomics in the field of red meat science has yet to be unlocked. Indeed, further developments in metabolite analysis (lower detection limits, improved extracting protocols or faster sample handling) will lead to a more complete profiling of potential biomarkers. Applications for authentication, detecting spoiling-associated compounds, metabolic profile for meat processed products, acquiring a better understanding of ageing and post-mortem practices, detection of the impact of feeding and production practices, or for the investigation of the quality variations among breeds or for the study of certain meat quality defects are the current important and challenging 
topics. Metabolomics is well positioned to provide some important advances in this regard (for review: Goldansaz et al., 2017). A number of excellent examples were highlighted by these authors in their review including metabolome discovery for normal metabolite composition and concentrations, identification of biomarkers as well as production traits in dairy and beef cattle. Moreover, metabolomics is considered as an emerging tool for meat authentication. For example, an earlier study using an NMR-based metabolomics was able to discriminate beef originating from four countries: Korea, New Zealand, Australia and the United States (Jung et al., 2010). In this study, the major metabolites responsible for differentiation in orthogonal projection to latent structure-discriminant analysis (OPLS-DA) loading plots were succinate and various amino acids including isoleucine, leucine, methionine, tyrosine and valine. The use of a mass spectrometry-based untargeted metabolomics for differentiation of beef samples from different geographical origins, namely the United States, Japan and Australia, and feeding regimes was also found to be a relevant approach (Man et al., 2021). Another study by Osorio et al. (2012) investigated the use of an NMR-based metabolomics to authenticate beef on the basis of the preslaughter production system. The authors used both urine and muscle samples from animals fed either pasture outdoor, a barley-based concentrate indoor, silage followed by pasture outdoor or silage followed by pasture outdoor with concentrate over $1 \mathrm{yr}$. The results showed that separation according to production system was possible indicating the potential use of this approach in beef authentication. Identification of the major discriminating peaks in urine led to the identification of potential markers of the production system including creatinine, glucose, hippurate, pyruvate, phenylalanine, phenylacetylglycine and three unassigned resonances (Osorio et al., 2012).

\section{Rapid and non-destructive methods to predict the quality of fresh meat}

Rapid non-destructive spectrometric methods have shown potential in the context of objective carcass and meat quality assessment (Allen, 2021). Spectroscopy is the term given for the interaction that occurs between radiation and matter. When radiation interacts with a sample, the radiation may be transmitted, reflected or absorbed. The contribution of these three phenomena is dependent on the samples' physical specifications and chemical constitution (Nicolaï et al., 2007). Near-infrared spectroscopy (NIRS) is a form of spectroscopy predominantly involved in the direct measurement of the vibrations of $-\mathrm{CH},-\mathrm{SH},-\mathrm{OH}$ and $-\mathrm{SH}$ bonds (Prieto et al., 2017), whereas other vibrational spectroscopic techniques such as Raman spectroscopy are involved in the measurement of inelastic scattering of light (Cama-Moncunill et al., 2020). When the sample is irradiated, its special characteristics undergo changes through various wavelength-dependent scattering and absorption processes. NIRS combined with advanced multivariate statistical techniques has been shown to be an effective tool for the prediction of quality traits in many food applications, including in red meat (Prieto et al., 2017; Moran et al., 2018; Cafferky et al., 2020). NIRS has also been proven as an effective method for species identification in meat, with Mamani-Linares et al. (2012) able to successfully determine cattle, llama and horse meat from homogenised meat samples with an accuracy of $89-100 \%$. Using NIRS as an authentication tool in meat, Moran et al. (2018) were able to classify beef ageing time with an accuracy of $94-100 \%$.

Major advantages of NIRS are the speed at which it can be applied, and its non-destructive nature as there is no necessity for sample preparation in most settings. NIRS technology has been used for determination of various quality traits in muscle foods at-line, on-line and off-line. Spectral information on final meat composition is also an effective tool to allow producers to adapt and optimise dietary supplementation and feeding regimes to suit the needs of their consumers (Weeranantanaphan et al., 2011), while rapid measurement technologies have the potential to be utilised by breeders as methods of improving meat quality traits during genetic selection. The use of NIRS for the prediction of textural traits such as WBSF values and trained sensory panel scores in meat is a topic which would have important application in meat plants, as both WBSF and trained sensory analysis are timeconsuming and destructive; however, due to the complexity involved in the prediction of these traits, the coefficients of determination presented in the literature are variable (De Marchi, 2013; Cafferky et al., 2020).

The potential of single-point, and to a lesser extent, multipoint, spectroscopy for the accurate and representative prediction of meat quality attributes on intact samples is dependent on the heterogeneity of the meat, which is a challenge due to the complexity of the tissue structure in any given cut, and the non-uniform distribution of its constituents (Savoia et al., 2020). Hyperspectral imaging (HSI) represents a more advanced approach with the potential to overcome this limitation. $\mathrm{HSI}$ can record images of the entire sample surface and at each pixel location a wide spectrum across defined wavelengths is acquired. HSI therefore records spatially defined chemical information. An HSI image can cover the chemical signature of the entire sample at different spatial and spectral resolutions, although the increase of the data accuracy requires more time, more complex and expensive instruments and a higher computational power for the management of bigger data sets. Therefore, several studies have examined the relevance and assessed the accuracy of $\mathrm{HSI}$ for the prediction and classification of meat quality traits. Already at the beginning of the decade, successful performances were shown for the assessment 
of colour, $\mathrm{pH}$, tenderness (both instrumental and sensory), major muscle constituents and water-holding capacity in beef (ElMasry et al., 2011, 2012) and lamb (Kamruzzaman et al., 2012, 2013). Most recently, Antequera et al. (2021) described the development of non-destructive methodologies (i.e. HSI, NMR and magnetic resonance imaging [MRI]) to determine quality characteristics of fresh meat that gave accurate and promising results. The studies on the applications of the $\mathrm{HSI}$ are mainly at laboratory scale and based on benchtop instruments, hence it is desirable that further advances orient towards factory solutions and applications to provide fast, accurate and real-time information.

Two hyperspectral systems for the image acquisition of ribeye muscle on beef carcasses in processing plants were proposed at $2 \mathrm{~d}$ post slaughter (Konda Naganathan et al., 2015a, 2015b). In these two studies, the classification of beef, based on tenderness at $14 \mathrm{~d}$, gave promising results in terms of accuracy and scanning/processing times. Dixit et al. (2021) assessed and compared the performances of two spectroscopy and three $\mathrm{HSI}$ automated measurement systems on intact $M$. longissimus thoracis et lumborum sections in a meat-processing pilot plant. Prediction models for $\mathrm{pH}$ and Intramuscular fat (IMF) were presented and the HSI linescan provided prediction validation powers of 0.89 and 0.90 , respectively. The development of $\mathrm{HSI}$ systems for the online implementation in slaughter and processing plant environments holds a lot of promise, though continued improvement of accuracy and reduction in scanning time are necessary.

\section{Post-mortem interventions for beef tenderness improvement}

The variability in beef tenderness is related to several factors ranging from farm to fork (Gagaoua et al., 2018b, 2018c, 2019a, 2019c; Holman \& Hopkins, 2021) as a result of intricate interconnected biochemical mechanisms (Gagaoua et al., 2021b). However, it is well acknowledged that, outside of extreme situations such as much older animals, postmortem factors are the main influencers when we consider meat tenderness. The level of variability evident within a particular meat cut, especially the valuable pieces such as striploins, is a serious concern for both consumers and the meat industry (Maher et al., 2004). Therefore, several post-mortem interventions are outlined in the following text, which have made, or are expected to make, significant improvements in the tenderness outcomes. Not included in this review, but of interest, is the application of enzymatic treatments using exogenous proteases and the conventional (applied) methods for meat tenderisation such as electrical stimulation, mechanical tenderisation (blade/needle tenderisation, flaking, mincing) and contraction-prevention (stretching/tenderstretch/alternative hanging, tendercut ${ }^{\mathrm{TM}}$, wrapping, rapid crust freezing) (for details refer Bekhit et al.,
2014; Bhat et al., 2018). For details on the recovery methods (Hafid et al., 2020; Gagaoua, 2021) and use of exogenous enzymes to tenderise meat, we invite the reader to refer to the recent review by Gagaoua et al. (2021a) on the latest studies and other emerging methods that combine proteases to physical intervention methods some of which are described in the following text (Santos et al., 2020; Botinestean et al., 2021).

Ageing methods including dry ageing to improve beef tenderness

After critical early biochemical events such as apoptosis, $\mathrm{pH}$ decline and rigor-mortis, the maturation period commences leading to improvements of both the texture and sensory aspects of meat (Ouali et al., 2013). Ageing consists of a number of biochemical processes that are mainly related to the breakdown of muscle proteins, namely those of structure by endogenous proteolytic enzymes leading to the appearance of new protein fragments (Gagaoua et al., 2021c). In fact, two main effects can be observed: a progressive increase in tenderness, as the muscle structure is disintegrated, and a release and accumulation of peptides and free amino acids. Such molecules have an impact on colour (Gagaoua et al., $2020 b$ ) and other quality attributes, but more importantly as precursors of flavour (Kim et al., 2018).

Ageing methods can be classified into wet and dry ageing. By far, the most relevant at the industrial level is the former, in which the moisture content is kept as constant as possible, while in the latter, water evaporation is desirable. Advances in packaging materials with high barrier properties for water allowed the development of the wet ageing process, in which primal cuts are vacuum packed and stored under controlled conditions. At the end of the ageing period, an improvement in yield, processing and shelf life is obtained when compared to dry ageing (Ha et al., 2019a). The most relevant processing factor for wet ageing is the required time. Typical ageing times are those between 14 and $21 \mathrm{~d}$, with no huge improvement beyond this point but different muscles do respond differently (Nair et al., 2019). Dry ageing is less popular due to high processing cost, extended ageing times and lower sealable yields, leading to an increased purchase price; however, recent niche market trends indicate that dryaged beef is growing and attracting more consumers (Álvarez et al., 2021).

Dry ageing is described as the process of storing post-rigor meat, generally without protective packaging, under controlled conditions of humidity, temperature and airflow for a certain time, typically more than 4 wk (Álvarez et al., 2021). As a consequence, there is a concentration of typical compounds responsible of the "dry-aged flavour" providing aromas such as nutty, roasted or buttery (Flores, 2017). According to Ramanathan et al. (2020), wet ageing flavours tended to be 
described as sour, metallic and bloody flavours, which are not evident in dry-aged meat. There is still controversy whether dry ageing can improve beef tenderness when compared to wet ageing; in any case, the main reason for dry-aged beef is its differential flavour and aroma profile. Recent investigations have demonstrated that dry ageing could also improve the palatability of low marbled beef (Ha et al., 2019b).

A third type of ageing has been recently developed, in which previous methods are combined in a stepwise dry/wet ageing process (Kim et al., 2018). In this case, the meat was dryaged for $10 \mathrm{~d}$ and then packaged and wet-dried for extra $7 \mathrm{~d}$.

Physical intervention methods to improve the texture of fresh meat quality

Other methods to improve beef tenderness (including muscle proteins digestibility) revolve around post-slaughter interventions using physical methods capable of manipulating the muscular, cellular or protein structure of meat (Bekhit et al., 2014; Warner et al., 2017; Bhat et al., 2021). Among these, the most studied emerging methods include high hydrostatic pressure (HPP), pulse electric fields (PEF), ultrasound (US) and hydrodynamic shockwaves (HSW), although others such as electrical stimulation can also be effective (for review: Hwang et al., 2003; Abhijith et al., 2020).

Bolumar et al. (2021) recently reviewed in detail the mechanisms of action of HPP based on the pressure applied, ranging from 100 to $900 \mathrm{MPa}$. It seemed that HPP can influence muscle structure breakdown and in particular modifications at the I-band and $\mathrm{M}$-line in addition of the fragmentation and polymerisation of myosin and the activation of the proteolytic enzymes. High hydrostatic pressure can be applied to prerigor muscles, with optimum tenderisation around $200 \mathrm{MPa}$, for $4 \mathrm{~min}$ and temperatures between 30 and $35^{\circ} \mathrm{C}$ (for beef and lamb), although higher pressures may be required for pork. When applied to post-rigor muscle, although it can be performed at lower temperatures, more consistent results are achieved at temperatures $>25^{\circ} \mathrm{C}$ (Sikes \& Warner, 2016).

The application of PEF in the meat industry has been recently reviewed (Bhat et al., 2019), and the exact mechanisms by which PEF promotes meat tenderisation are not fully elucidated. As for HPP, it has been proposed that PEF can lead to a physical disruption of the muscle structure, although modification of the enzymatic system seems more plausible. Further, it has been suggested that PEF induces calcium release, which may influence the activity of certain proteolytic enzymes such as the calcium-dependent proteases, that is, calpains in addition to the impact on glycolysis rate (Warner et al., 2017). However, the tenderisation effect of PEF is not immediate, and a further ageing process is required. When post-rigor meat is treated, contradictory results have been observed in the literature; while some authors did not find any significant improvement in the shear force (Suwandy et al., 2015a, 2015b), other authors reported an improvement of beef tenderness (Mungure et al., 2020). A similar scenario was observed for hot-boned muscles (Warner et al., 2017; Bhat et al., 2019). Arguably, the final impact of PEF on post-rigor meat strongly depends on muscle type and processing parameters (frequency, number and duration of pulses and intensity).

Ultrasound is widely applied in food industry for several purposes, for instance, to improve meat quality traits by modulating $\mathrm{pH}, \mathrm{WBSF}$ and water-holding capacity (Kang et al., 2021), and also to induce structural changes in post-mortem muscle (Alarcon-Rojo et al., 2019). The main mechanism seems to be through calcium release and the enhancement of the activity of lysosomal enzymes, hence leading to an increased overall proteolytic activity in post-mortem meat (Kang et al., 2021). In addition, US seems to have an effect on connective tissue, by modifying its thermal characteristics, hence impacting the final tenderness.

Hydrodynamic shockwaves (HSW) was also recently proposed to improve tenderness of tough meat cuts by both inducing and accelerating the ageing tenderisation process (Ha \& Warner, 2021). Very briefly, this technology consists of the generation of pressure waves (up to $1 \mathrm{GPa}$ ) using water as the transmission fluid; such a wave pressure passes through the liquid and the meat matrix. The wave can be generated mainly using explosive or electrical devices. Because of the mechanism of action and considering the very short treatment time (milliseconds), it can be considered as a non-thermal treatment, although the transmission fluid needs to be monitored. The few studies that applied HSW reported that muscle structure is disrupted (Zuckerman et al., 2013); however, further studies are required to ascertain the role proteolysis plays in this regard (McDonnell et al., 2021). In any case, as reviewed by $\mathrm{Ha}$ and Warner (2021), there is an agreement about the positive impact that HSW has to improve meat tenderness.

\section{Recent advances in the management and prediction of safety and microbiology of fresh red meat}

It is well recognised that ruminant animals presented for slaughter are an important source of microbial contamination into the meat plant and for the carcass. Most of these microorganisms are of faecal origin, with some originating from the environment. Microbial contamination of meat carcasses may occur during slaughter and dressing operations, through direct or indirect routes. Such contamination may impact on meat safety, if pathogens such as Shigatoxigenic Escherichia coli (STEC) or Salmonella are present, and on spoilage and shelf life of the meat, depending on both the total microbial load and the specific spoilage causing microorganisms which 
may be present (Mansur et al., 2019; Ghougal et al., 2021). The shelf life of packaged meat products has been shown to correlate with the number and types of microbes on meat primals at the time of packaging in the boning hall and on the lag phase and growth rate of microorganisms during storage (Kaur et al., 2017).

\section{Interventions to control microorganisms in the fresh meat chain}

A range of intervention measures have been considered as a means to prevent or reduce microbial contamination of carcasses to reduce microbiological hazards further than what is achievable solely by adhering to good hygiene practices (GHP). Many of these interventions have been developed with the aim of reducing the level of STEC or Salmonella prevalence and concentration on beef carcasses and meat cuts (Buncic et al., 2014), but most are broadly antimicrobial and will also impact on the total microbial load and its composition. To implement an intervention, it is necessary to consider the regulatory status in local and export markets. It is also essential to take into account the required purpose, cost, space availability and infrastructure of the plant, in addition to environmental factors, such as waste and effluent disposal.

The role of the animal coat (hide/fleece) in introducing microbial contamination into the slaughter plant is well acknowledged and many countries have policies around cleanliness of livestock, as well as management practices for dirty animals at the abattoir. In some jurisdictions, cattle hides may be washed with chemical agents in the lairage. A meta-analysis of the literature showed that the use of sodium hydroxide or lactic acid for STEC hide decontamination gave mean log reductions of around 3.66 and 3.22, respectively (Zhilyaev et al., 2017). Finalyse ${ }^{\circledR}$ (marketed by Elanco Food Solutions, Greenfield, IN, USA) is a commercially available bacteriophage cocktail which can be sprayed on cattle hides in the lairage to specifically reduce the load of E. coli O157. However, in a United States feed-lot trial, Arthur et al. (2016) reported no significant reduction using this approach, with a prevalence of $51.8 \%$ E. coli $0157: \mathrm{H} 7$ on cattle hides receiving phage treatment compared to $57.6 \%$ on untreated hides. Regulatory restrictions in the EU do not currently permit the use of chemical washes and bacteriophages on bovine hides. Slaughter facilities rely on good dressing procedures during de-hiding/de-fleecing to minimise contamination of the carcass. Additional GHP measures may be used to remove visible faecal material from carcasses pre-evisceration, including carcass washing and knife trimming. Evidence for their impact on pathogen reduction is limited. Steam vacuuming may be used for spot cleaning along the cut line after hide/fleece removal and before evisceration. This is a handheld device consisting of a vacuum wand with a hot spray nozzle, delivering water at $88-94^{\circ} \mathrm{C}$ to the carcass surface under pressure, while simultaneously vacuuming the area. Research has shown that this treatment could reduce microbial counts on carcasses, but reported results are highly variable with aerobic plate count reportedly reduced by around $3 \pm 0.14 \mathrm{log}$, and total coliform and $E$. coli counts by $4.0 \pm 0.12$ log (Dorsa et al., 1996a, 1996b). A meta-analysis showed a mean log reduction of $E$. coli of $3.1 \log 10 \mathrm{cfu} / \mathrm{cm}^{2}$ (Zhilyaev et al., 2017). The success of the method is very dependent on both the training and performance of the operator.

Interventions may be applied to the carcass post dressing and pre chill to reduce microbial contamination on the carcass surface. Currently, only potable water (hot water and steam pasteurisation) and a lactic acid wash for beef carcasses are permitted for use in the EU. In other jurisdictions, however, there is regulatory approval for the use of a wide range of carcass interventions. Water at varying temperatures may be used to wash the dressed carcass at the pre-chill stage. The temperature achieved on the carcass surface is affected by the temperature of the water, the volume of water, the distance between the spray nozzles and the carcass and the pressure at which the water is applied. A commercial hot water wash cabinet at $74^{\circ} \mathrm{C}$ for $5.5 \mathrm{~s}$ was reported to reduce both total viable count (TVC) and Enterobacteriaceae counts by a mean of $2.7 \mathrm{log} \mathrm{cfu} / \mathrm{cm}^{2}$ and reduced the prevalence of $E$. coli 0157:H7-positive carcasses by $81 \%$ (Bosilevac et al., 2006). The meta-analysis cited above estimated that increasing the temperature of water may also increase the effectiveness in reducing $E$. coli by 0.014 log cfu/cm ${ }^{2}$ per ${ }^{\circ} \mathrm{C}$ (Zhilyaev et al., 2017). A study using hot water at $85^{\circ} \mathrm{C}$ in a spray cabinet at $15 \mathrm{lb} /$ inch $^{2}$ (60 cycles) against a cocktail of STEC serogroups inoculated on to beef flank indicated significant reduction (3.3 to 4.2 log reduction) in STEC (Kalchayanand et al., 2012).

Organic acid (lactic, formic, propionic, citric, fumaric, L-ascorbic acid and acetic) washes have been applied to carcasses. Internationally, solutions of lactic or acetic acids $(1-3 \%)$ are the most frequently used chemical interventions in commercial plants for both beef and lamb dressing. Lactic acid gives mean reductions of $2.07 \log 10 \mathrm{cfu} \mathrm{cm}^{2}$ in E. coli (Zhilyaev et al., 2017) and about $1.1 \mathrm{log}$ in total bacteria (Ransom et al., 2003). Regulations (EC) 101/2013 permit the use of lactic acid on beef, though not on lamb, for surface decontamination of whole carcasses, halves or quarters. It can be applied at a concentration of $2-5 \%$ and prepared in potable water under $55^{\circ} \mathrm{C}$. It can only be applied at the stage before chilling or refrigeration and must be applied under controlled and verifiable conditions and integrated into a HACCP (Hazard Analysis \& Critical Control Point)-based management system. Other chemical and physical interventions allowed on the carcass in some jurisdictions include the use of trisodium phosphate, chloride dioxide, acidified sodium chloride and cetylpyridium chloride, all of which give reported reductions of generally 1-2 log $\mathrm{cfu} / \mathrm{cm}^{2}$ in total bacteria and also give 
reductions in pathogens such as E. coli $\mathrm{O} 157$ (Wheeler et al., 2014).

The objective of chilling carcasses is to cool the meat quickly enough to prevent bacterial growth but not so quickly as to cause cold shortening of the meat. The higher the carcass surface temperatures the more likelihood there will be for bacterial growth, including spoilage bacteria. The length of time that carcasses are in the chill room prior to bone out will also impact on growth of psychrophilic aerobic bacteria and may result in primals that have higher bacterial counts (Bieche-Terrier et al., 2019).

A variety of meat packaging systems are available, ranging from air-permeable packaging for short-term storage and retail display of raw chilled meat to modified atmospheric packaging (MAP), and vacuum packaging for longer-term storage. In terms of packaging materials, the oxygen and carbon dioxide permeability, water transmission rates, seal reliability, antifogging properties and resistance to puncture are key characteristics which, together with the temperature of storage, will have a significant impact on the shelf life of fresh meat (Mills et al., 2014). It should be noted, however, that the shelf life of meat is limited not only by the microbiological load and profile, but also by organoleptic factors such as colour, odour, flavours and so on and should to be taken into consideration in terms of achievable shelf life.

\section{Characterising microorganisms in fresh meat production}

The spoilage of stored meat is mainly due to the growth and dominance of undesirable bacteria, and the composition of the microflora is as important as the total microbial load. The conditions during carcass chilling and during meat storage will greatly influence the lag phase and growth rates of bacteria, and may be selective for particular groups of bacteria associated with the spoilage of refrigerated fresh beef and lamb meat. Table 1 highlights the types of spoilage which may be caused by different groups of bacteria.
There is, however, a need for improved knowledge about the composition of the total meat microflora, to allow a better understanding of meat spoilage development. While the use of culture-based methods can detect a limited range of bacteria, recent advances in molecular tools, such as sequencing, including amplicon sequencing which is most commonly based on sequencing the 16s rRNA region, allow the composition of the total microflora to be ascertained. Such information about the development and changes in the composition of the microbial community on vacuum-packed beef and lamb during storage will give a better understanding of how spoilage develops and improved shelf life prediction.

\section{Sequence-based approaches for understanding microbial community composition}

Recent years have seen a rapid improvement in the availability, accessibility and quality of DNA and RNA highthroughput sequencing methodologies (often termed next-generation sequencing), which have revolutionised microbiological studies and have many varied applications for food microbiology, including supporting product safety and shelf life assessments. Continued improvements in analytical pipelines and cost reductions are facilitating a movement from the use of sequencing solely for research purposes to more widespread applications within industry, including the agri-food sector. There are two predominant sequencing applications in food microbiology. Whole-genome sequencing (WGS) is utilised to provide the complete genomic sequence of individual microbial isolates (Bergholz et al., 2014). Microbial community compositional analysis, on the other hand, identifies all microorganisms, or subsets thereof, in a sample. It can be facilitated through either metagenomic sequencing, where all DNA in a sample is sequenced and the microbiome identified, or amplification of specific genes (e.g. $16 \mathrm{~S}$ rRNA gene for bacterial analysis or the fungal ITS region) allowing taxonomic identification of the species present.

Table 1: The type of spoilage caused of different types of bacteria

\begin{tabular}{lr}
\hline Microorganisms & Type of spoilage on beef and lamb \\
\hline $\begin{array}{l}\text { Pseudomonas spp. } \\
\text { Clostridia spp. }\end{array}$ & $\begin{array}{c}\text { Slimy appearance and sulphurous off odours } \\
\text { Shewanella putrefaciens }\end{array}$ \\
$\begin{array}{l}\text { Psychrotrophic Enterobacteraceae including } \\
\text { Hafnia, Serratia, Rahnella aquatilis, Yersinia }\end{array}$ & $\begin{array}{c}\text { Off flavours described as cheesy, malty/acidic, slimy appearance on meat, greening } \\
\text { of meat when vacuum pack is opened, unpleasant sulphide odours }\end{array}$ \\
$\begin{array}{l}\text { Brochothrix thermosphacta, } \\
\text { Brochothrix campestris }\end{array}$ & Strong odours described as cheesy or dairy or eggy odours, bubbles in vacuum pack, \\
Lactic acid bacteria including & green drip in vacuum pack, meat discolouration \\
Lactobacillus, Carnobacterium and Leuconostoc spp. & Souring \\
\hline
\end{tabular}


Subtyping of bacterial pathogens is central to public health epidemiology, helping identify outbreaks, track transmission and identify sources of infection. Depending on the pathogen, a number of methods have been used for this purpose by regulatory authorities and public health agencies, such as pulsed field electrophoresis, multi-locus sequence typing, multiple-locus variable number tandem repeat analysis and others. However, these came with limitations, including suboptimal precision (Brown et al., 2019). Whole-genome sequencing has revolutionised this field, providing the possibility of sequencing a complete bacterial genome in a quick and cost-effective manner, providing unprecedented precision for comparing and tracking isolates. Concomitant improvements in the sequencing technology and associated bioinformatics pipelines, allied with increased accessibility and decreasing costs, have supported a rapid implementation of the technology to enhance food safety and public health worldwide and it is now used for prospective surveillance of bacterial foodborne pathogens in a number of countries (Jagadeesan et al., 2019).

In addition to its use in subtyping and comparing isolates, WGS analysis has also found applications within the meat industry, particularly for identifying routes of pathogen contamination within production facilities, or the presence of persistent isolates. Such studies support the implementation of targeted controls to provide enhanced food safety assurance. For example, a Norwegian study compared 252 Listeria monocytogenes isolates from four meat-processing facilities over an 8-yr period by WGS and was able to demonstrate the presence of this specific sequence type across a number of unrelated facilities, repeated detection of specific clones within specific zones over a number of years, the introduction of clones through the installation of secondhand equipment and cross-contamination routes (Fagerlund et al., 2020).

In addition to WGS, advances in sequencing technologies have provided the opportunity to gain a far greater understanding of the total microbial community composition of different ecological niches and how they change over time. Not all microbial species within a given environment are culturable in standard laboratory conditions, but they may nonetheless have a significant impact on the microbial community function. Culture-independent technologies such as sequencing facilitate a more in-depth understanding of the species present and, with some approaches, their metabolic activity.

Many studies to date have focused on the use of ampliconbased sequencing for examining the bacterial community composition of meat carcasses and products, with 16S rRNA as the most commonly used target gene for sequencing. Other genes, such as gyrB, have also been proposed for such studies to provide greater discriminatory potential (Poirier et al., 2018). Such studies have been used to examine the impact of various abattoir setups and practices (Stellato et al., 2016; Korsak et al., 2017) and the impact of storage and/or packaging conditions (Wang et al., 2016; Kaur et al., 2017). In some cases, such analysis has been undertaken with parallel analysis of metabolites such as volatile organic compounds to provide further understanding of spoilage (Mansur et al., 2019). A recent study examining the impact of meat industry sanitation processes combined RNA-based $16 S$ rRNA amplicon sequencing with plate counts to map the viable microbiota and to define any specific bacterial group inactivation (Botta et al., 2020). Some amplicon-based studies have also used software tools such as PICRUSt to predict and compare metabolic activities of microbial communities from different sample types such as the abattoir environment or the meat itself (Stellato et al., 2016).

Shotgun-based metagenomic studies, where all DNA in a sample is sequenced, allow for identification of individual strains, analysis of metabolic pathways, presence of antimicrobial resistance and virulence genes. Studies of this nature focused on the microbiome of meat and meat production and processing facilities remain rare to date. This is likely due to the increased cost and computational complexity in analysing the results in comparison to amplicon-based studies. A recent study utilised such an approach for pathogen detection along the beef production (Yang et al., 2016), but it is acknowledged that such studies are hampered by the absence of well-curated and high-quality databases relevant for food safety management, and the incomplete functional annotation of genes in public databases (Jagadeesan et al., 2019). Nonetheless, with an increased acknowledgement of the need to consider the complete microbial community, as opposed to single species, and the importance of ecological interactions in understanding food systems, it is likely that such studies will become more common. Meta-transcriptomics focuses on sequencing the RNA within a sample, enabling a focus on the viable microbial community and also gene expression within that community, providing an understanding of the metabolic activity of the microbial community. For example, Hultman et al. (2020) utilised meta-transcriptomics to analyse a modified atmosphere-packaged beef during storage and was able to identify changes in active metabolic pathways related to spoilage onset.

A number of challenges exist for the routine application of sequencing in the meat sector. These include, but are not limited, to the diversity of sample types and matrices, the presence of inhibitory substances, the viability of the microbial community present, low cell numbers, DNA concentration and quality, lack of standardisation in sequencing and analysis and the composition of available databases. Notwithstanding these challenges, however, the potential of the technology is immense in relation to meat safety and quality management. 
Monitoring of microorganisms in fresh meat production To support the goal of achieving consistently low microbial counts on meat carcasses and meat cuts, there is need for at- or near-line monitoring of microorganisms to support real-time process control and management as part of HACCP systems. While conventional microbiological methods including culturing and colony-counting can detect low numbers of cells, they require several days to obtain a result (Wang et al., 2018) and are thus unsuitable for online monitoring and process control in meat production processes (Wang et al., 2018; Achata et al., 2020). There are a number of emerging techniques which could be used near-line or atline based on fluorescent sensors, spectroscopic and spectral imaging techniques, such as infrared spectroscopy (IRS), Raman spectroscopy, fluorescence spectroscopy, HSI and multispectral imaging (MSI) for the rapid detection of total or specific microorganisms in meat. These are attractive methods due to the rapid, non-destructive nature of sample examination. Moreover, the potential for online monitoring in meat production facilities would provide a quicker method than the conventional time-consuming methods.

Optical oxygen microrespirometry assay, based on a commercial GreenLight ${ }^{\mathrm{TM}}$ probe (Luxcell Biosciences, Cork, Ireland), is a microtitre-based plate assay providing a rapid high-throughput method to determine aerobic bacterial load assessment on fresh meat, based on analysis of microbial oxygen consumption (Fernandes et al., 2019). In this test, the probe produces a large increase in fluorescence on the depletion of dissolved oxygen by growing microorganisms, which occurs when a certain threshold of respiration is reached. The time required to reach this increase in signal can be used to calculate the cfu/g of the original sample, based on a predetermined calibration (Fernandes et al., 2019). The authors showed that the GreenLight ${ }^{\mathrm{TM}}$ method enabled the detection and enumeration of aerobic microorganisms (TVC) within $12 \mathrm{~h}$ at contamination levels from $10^{3} \mathrm{cfu} / \mathrm{g}$ in selected raw meats, beef, lamb, and pork and showed good agreement with the standard conventional culture method (ISO 4833:2003) for the enumeration of aerobic microorganisms at $30^{\circ} \mathrm{C}$ with a Pearson correlation coefficient value of 0.96 . The application of this promising method, however, requires further investigation in commercial meat plant settings.

Achata et al. (2020) assessed the potential of HSI in the visible $(445-970 \mathrm{~nm})$ and NIR $(957-1664 \mathrm{~nm})$ range with chemometrics in the prediction of TVC in beef. Partial least squares regression (PLSR) and principal components analysis (PCA) were compared, along with a variety of spectral preprocessing techniques and band selection methods before data fusion combined the information, which produced a more accurate model. Data fusion for both spectral regions successfully produced TVC prediction models for beef stored at $4^{\circ} \mathrm{C}\left(R^{2}=0.96\right), 10^{\circ} \mathrm{C}\left(R^{2}=0.94\right)$ or at either 4 or $10^{\circ} \mathrm{C}$
$\left(R^{2}=0.86\right)$. Tao et al. (2015) used hyperspectral scattering imaging in the VIS/NIR range $(400-1100 \mathrm{~nm})$ combined with Lorentzian function to predict low-level bacterial contamination on beef. Data were modelled using multivariate statistical analysis methods including principal component regression (PCR), PLSR and back propagation neural network (BPNN). While the prediction models did not perform well using individual Lorentzian parameters, the combination of parameters yielded improved models for determining low levels of beef TVC by PCR $\left(R^{2}=0.86\right)$, PLSR $\left(R^{2}=0.87\right)$ and BPNN $\left(R^{2}=0.90\right)$ methods.

Another spectral imaging technology is mass spectrometry imaging (MSI), which is based on $\mathrm{HSI}$ technology. In $\mathrm{HSI}$, the three-dimensional (3D) hypercube is composed of full wavebands, providing a full spectrum for each pixel. MSI also provides a $3 \mathrm{D}$ hypercube; however, rather than obtaining a continuous full spectral range, MSI obtains discrete noncontinuous bands (Panagou et al., 2014). As a result of fewer spectral bands being examined, MSI systems do not provide the detailed fingerprints of $\mathrm{HSI}$; however, instrument costs and complexity are reduced and data acquisition time is significantly lower than $\mathrm{HSI}$. In MSI, the sample is placed inside a white sphere (Ulbricht sphere) which is illuminated by light-emitting diode (LED) lights which uniformly distribute the spectral radiation, and finally the reflection from a specific wavelength is recorded by a camera at the top (Gowen et al., 2015). Panagou et al. (2014) evaluated an MSI system in monitoring aerobically stored beef at chilled and abuse temperatures using 18 wavelengths ranging from UV ( $405 \mathrm{~nm})$ to short wave NIR $(970 \mathrm{~nm})$. The beef samples were classified into three different classes based on the TVC values and PLS discriminant analysis (PLS-DA). PLSR models were also developed to predict the TVC ( $r p=0.783$, root mean square of error prediction $[\mathrm{RMSEP}]=1.291)$, Pseudomonas spp. $(r p=0.837$, RMSEP $=1.116)$ and Brochothrix thermosphacta $(r p=0.859$, RMSEP $=0.996)$ levels present on the beef fillets. Estelles-Lopez et al. (2017) compared data from MSI, electric nose, high-performance liquid chromatography (HPLC), Fourier-transform infrared spectroscopy (FTIR) and gas chromatography coupled with mass spectrometry (GC-MS) using "MeatReg", a web-based application which identifies the best machine-learning regression models for microorganism prediction in minced beef under aerobic and MAP conditions. MSI data from 18 non-uniformly distributed wavelengths in the visible and NIR region (405-970 nm) were acquired. The prediction models obtained from MSI data provided accurate measures of TVC $($ RMSE $=0.584)$, Pseudomonas spp. (RMSE $=0.853)$, B. thermosphacta $(\mathrm{RMSE}=0.685)$, Enterobacteriaceae $(\mathrm{RMSE}=0.658)$ and LAB (RMSE $=0.495$ ) using PLSR or random forests regression (RF-R) during aerobic storage, with similar results obtained for MAP samples. 
Overall, these type of spectral technologies offer potential for at- or near-line measurements of microorganisms, supporting process- and hygiene-control measures as part of HACCP plans but they require further validation and robustness assessments within industrial conditions.

\section{Future challenges and opportunities for the management and prediction of safety and microbiology of fresh red meat}

From the above, it seems that a number of opportunities exist for beef and lamb processors to achieve the ambitions of significant shelf life extension of fresh meat with assured safety by incorporation of microbial decontaminants and inprocess microbial monitoring. However, there are significant challenges with regulatory barriers in EU, production systems and logistics of slaughter plants. There is clearly no single solution to achieve extended shelf life. Therefore, an approach based on a series of intervention and management strategies along the complete meat chain, from animal through to storage and distribution of the packaged meat, will reduce contamination on the meat and the sources of crosscontamination in the factory environment (air, meat contact surfaces such as conveyors belts, etc.). When applied in combination, this will enhance and ensure meat safety, reduce spoilage events and significantly extend the shelf life of beef and sheep meat.

\section{Recent advances in sensory analysis applied to fresh red meat}

Consumers' desire to purchase and consume red meat is mainly driven as highlighted previously by its sensory properties of which tenderness, juiciness and flavour are considered the most important traits (O'Quinn et al., 2018). Indeed, it has been reported that few humans have an intrinsic distaste for meat, but rather an innate preference for the sensory sensations it imparts during eating (Frank et al., 2017). Thus, the application of the human senses in understanding meat sensory attributes and their relationship to perceived eating quality has grown significantly over the past several decades (Djekic et al., 2021).

Sensory analysis provides a set of scientific techniques to better understand the sensory properties of meat and consumer responses to these properties. In conjunction with instrumental and/or biochemical studies, human sensory data provide the best models for predicting how consumers are likely to perceive the eating quality of meat (Lawless \& Heymann, 2010) as it was the case of the Meat Standards Australia system (for reviews: Watson et al., 2008a, 2008b). Within the meat science community, sensory analysis of meat has been traditionally divided into two clearly defined areas: 1) analytical tests, aimed at objectively evaluating the sensory properties of meat using discriminative or descriptive techniques, and 2) hedonic tests, in which consumers provide information regarding their acceptance/preference (Warner et al., 2021). While these methods are recognised as valuable tools for generating data relating to various aspects of meateating quality, they are also time-consuming, costly and lack the flexibility required for successful commercialisation in today's fast-paced industry environment. Moreover, the need for sensory information is becoming more complex as consumer purchase decisions increasingly take account of extrinsic factors including environmental concerns, animal welfare, sustainability and perceived healthfulness, in addition to traditional intrinsic quality cues (Frank et al., 2017; Warner et al., 2021). As the industry continues to expand into new and emerging markets, there is a need to develop and adopt novel and rapid sensory techniques to generate data that are more reflective of consumer assessments in the real world without compromising the quality of results.

Therefore, several new rapid sensory techniques including check-all-that-apply (CATA), rate-all-that-apply (RATA), napping and flash profiling have been recently applied to study the sensory characteristics and consumer acceptance of a range of muscle foods (Pintado et al., 2016; de Andrade et al., 2018). While there has been little to no application of these methods to fresh red meat, the findings to date have been promising, with studies reporting sensory maps comparable to those obtained from traditional descriptive analysis with trained panels (Ruiz-Capillas et al., 2021). However, as the application of these methods to fresh red meat is limited, research is strongly needed to establish the reliability and reproducibility of these new approaches for consumer sensory evaluations of beef.

Other recent advances in sensory analysis in the context of fresh red meat has been in the use of dynamic sensory methods such as temporal dominance of sensations (TDS) and temporal liking. The sensory properties of meat pieces perceived while eating change dynamically as they are broken down and manipulated in the mouth. Therefore, the sensory properties perceived in the earlier stages of eating are very different to those perceived at the end. Traditional sensory techniques typically provide a quantification of perceived intensity after eating, and thus fail to consider the dynamic aspect of in-mouth sensory perception. For example, TDS has recently been used to study the dynamics of sensory perception of Wagyu beef (Watanabe et al., 2019). The study showed that in addition to providing a good overall description of the sensory characteristics of Wagyu beef, the TDS method revealed new information regarding the dynamics of sensory perception as impacted by different cooking methods and fattening periods. In another study, a combination of traditional and temporal liking methods were 
used to compare consumer liking of striploin beef steaks from three different feeding systems (Corcoran et al., 2020). They reported that while consumers generally found the traditional method easier to perform, the temporal liking method provided more discriminatory data regarding the impact of animal diet on consumer liking during consumption. Taken together, these studies show that temporal methods can be applied to understand the dynamic nature of meat sensory attributes during eating and may provide information close to, or indeed superior to, that obtained using descriptive analysis, in a quicker and more cost-effective manner.

Beyond the application of new sensory methods, meat scientists should also consider the type of statistical approach used to analyse consumer sensory data. Consumers' mean acceptance ratings of meat and meat products are often used rather than comparing consumer segments as commonly done in marketing or consumer research (Miller, 2020). While popular multivariate techniques such as PCA and PLSR can account for some variation in consumer data, they often produce predictive equations that are not repeatable (Miller, 2020; Warner et al., 2021). The importance of taking into account consumer segmentation in consumer data analysis is based on the assumption that consumers have different likings and different drivers of liking, and thus using aggregated mean acceptance scores can conceal interesting and important findings. In addition, consumer segmentation or clustering techniques such as k-means, agglomerative hierarchical clustering or Gaussian mixture models (Gagaoua et al., 2018a, 2018c, 2019b) could be employed in conjunction with temporal assessment methods and open new research opportunities in meat science for segmenting consumers according to the evolution of their liking over time.

Across the meat industry to date, consumer sensory responses are collected using self-reported "explicit" measures, whereby consumers are typically instructed to assess a meat sample for liking in terms of tenderness, juiciness and flavour by indicating their response on a scale. However, consumer's purchasing decisions of meat are not solely based on sensory likes or dislikes and summarising all that complexity into a simple liking score is not sufficient to predict consumer response in today's market (Borgogno et al., 2017). Recently, considerable research efforts have been made to incorporate self-reported emotional measures in consumer sensory testing to better understand why food products that produce similar liking ratings perform vastly different in the marketplace (Crofton et al., 2019). Accordingly, Borgogno et al. (2017) used the EsSense25 method to investigate the emotions associated with beef consumption. The authors showed that presenting to consumers the same beef with different breeding information led to different emotions being evoked, and these differences in emotions were associated with different levels of meat liking. Within the meat industry, this type of information could enable a deeper understanding of consumer perception of products by considering data that move beyond simple liking measurements.

While numerous studies have captured consumers' emotional response towards the sensory profile of different food products, the techniques applied have relied on the use of selfreported measures, and therefore the accuracy of the data is dependent on the individual's ability to articulate their hedonic and emotional response to different sensory sensations (Crofton et al., 2019). Research has indicated that consumers' sensory acceptability of beef during eating is strongly linked to expectation formed at the point of purchase (Polkinghorne, 2018), but consumer expectation at the point of purchase is almost never captured in meat sensory testing. There are reasons for this, one of which is that this type of information is very difficult to collect as most people cannot articulate or describe their expectations or why they choose one product over another. It has been estimated that somewhere in the brain of $95 \%$ of human decision-making occurs on a subconscious level (Crofton et al., 2019). So, when consumers are choosing meat products in a retail setting, they are heavily influenced by factors that do not enter their conscious thought process. In addition, there are many sources of variation in consumer sensory responses that cannot be controlled in a sensory test, and as a result, panels of humans are by their very nature heterogeneous instruments for the generation of meat-eating quality data.

Recently, researchers have suggested using implicit or "biometric" techniques to measure consumers' subconscious sensory and emotional response to foods (Crofton et al., 2019; Miller, 2020). The most commonly studied techniques to date include capturing facial expressions using either electromyography (EMG) (Beyts et al., 2017) or a facial action coding system (de Wijk et al., 2012); recording eye movements using eye-tracking technology (Siegrist et al., 2019); and to a lesser extent, recording brain wave rhythms using electroencephalography (EEG) (Viemose et al., 2013). Other measures of interest include involuntary physiological responses governed by the autonomic nervous system (ANS) such as heart rate, skin temperature, respiratory patterns and skin conductivity. In addition, a sophisticated technique called functional MRI (fMRI) has provided interesting insights into which areas of the human brain changed after differing qualities of beef steaks were consumed, and how these changes are driving consumers' perceptions of tenderness, juiciness, flavour and overall liking (Tapp et al., 2017). While the application of implicit techniques in meat sensory research is in its infancy, these methods have the potential to provide a complex product characterisation over the entire eating experience in relation to how the temporal sensory profile of meat products influences consumers' hedonic and emotional response on both a physiological and behavioural level. 
In the comprehensive review by Crofton et al. (2019), virtual reality (VR) technology has been highlighted to provide an immersive and engaging opportunity for researchers to examine and manipulate the core structure of different food products, including meat. For example, using handheld controllers enables measurement data of different characteristics of foods' structure, by immersion into a VR setting (Crofton et al., 2021). Moreover, the work by Crofton and co-workers stated that VR could be applied as a context-enhancing technology, which will enable a more realistic consumer experience. Accordingly, Crofton et al. (2021) used VR as an emerging technological tool to understand the effects of eating context on consumers' sensory assessment of beefsteaks by comparing two different contexts, such as traditional sensory booths and a VR restaurant. It was concluded that consumers found the VR restaurant experience to be significantly more memorable in comparison to evaluating the beefsteaks in the traditional sensory booth. The results showed that the hedonic scores for all sensory attributes, including smell, tenderness, flavour and juiciness, were significantly greater for beefsteaks consumed in the VR restaurant, compared to the sensory booths. Further, overall liking scores were significantly higher for beef tested in the VR context.

Among the other emerging methods, Ross (2021) highlighted the benefits of using electronic tongue (e-tongue) in sensory food science. E-tongue was first used to discriminate the five basic tastes, therefore providing a valuable tool to food scientists, which will assist in enabling the evaluation of food quality, authenticity or the presence of residues. Tan \& Xu (2020), who reviewed the applications of electronic nose (e-nose) and e-tongue in food quality-related properties determination, concluded that both e-nose and e-tongue are useful tools to help in refining evaluation of different types of food quality characteristics compared to conventional detection methods. These methods are relatively low cost, rapid and efficient; however, a strict control of sample preparation, sampling and data processing are required for obtaining robust data, which could be positively correlated with consumer data. For meat applications, e-noses can be utilised to determine meat quality throughout smell evaluation such as freshness (Chen et al., 2019) or spoilage (Kodogiannis, 2018).

\section{Conclusion}

Recent advances in management and prediction of red meat quality (technological and sensory) have been discussed throughout this review. Many novel opportunities are presented through the application of a variety of foodomics approaches, which help not only in understanding the underlying causes of variability, but can also aid in both management systems delivering consistency in quality and in the development of innovative markers for quality. Further research in rapid non-destructive methods for predicting fresh meat quality is leading to important innovations and developments. Post-mortem carcass interventions are key factors in the management of the final eating quality, with a focus on ageing methods and physical interventions. Management and prediction of the safety and microbiology of fresh red meat cover interventions to control characterisation of microorganisms of relevance, advances in sequencebased approaches and monitoring systems. Many advances are also evident in relation to sensory analysis and understanding consumer motivators - areas which are of high interest for further research are outlined which are focused on advancing commercially relevant research themes to aid in the delivery of sustainable meat products that meet consumers' expectations.

\section{Acknowledgements}

Dr. Mohammed Gagaoua (MF20180029) and Dr. Alessandro Ferragina (MF20170219) are Marie Sklodowska-Curie Career-FIT Fellows funded by the Marie Sklodowska-Curie grant agreement No. 713654. The support of Meat Technology Ireland (MTI), a co-funded Industry/Enterprise Ireland project (TC 2016 002), to the authors is greatly acknowledged.

\section{References}

Abhijith, A., Dunshea, F.R., Warner, R.D., Leury, B.J., Ha, M. and Chauhan, S.S. 2020. A meta-analysis of the effectiveness of high, medium, and low voltage electrical stimulation on the meat quality of small ruminants. Foods 9: 1587.

Achata, E.M., Oliveira, M., Esquerre, C.A., Tiwari, B.K. and O'Donnell, C.P. 2020. Visible and NIR hyperspectral imaging and chemometrics for prediction of microbial quality of beef Longissimus dorsi muscle under simulated normal and abuse storage conditions. LWT 128: 109463.

Aiello, D., Patel, K. and Lasagna, E. 2018. The myostatin gene: an overview of mechanisms of action and its relevance to livestock animals. Animal Genetics 49: 505-519.

Alarcon-Rojo, A.D., Carrillo-Lopez, L.M., Reyes-Villagrana, R., Huerta-Jiménez, M. and Garcia-Galicia, I.A. 2019. Ultrasound and meat quality: a review. Ultrasonics Sonochemistry 55: 369-382.

Allen, P. 2021. Recent developments in the objective measurement of carcass and meat quality for industrial application. Meat Science 181: 108601.

Álvarez, S., Mullen, A.M., Hamill, R., O’Neill, E. and Álvarez, C. 2021. Chapter Three - Dry-aging of beef as a tool to improve meat quality. Impact of processing conditions on the technical and organoleptic meat properties. In: "Advances in Food and Nutrition 
Research", (ed. F. Toldrá), Academic Press, Oxford, United Kingdom, pages 97-130.

Antequera, T., Caballero, D., Grassi, S., Uttaro, B. and PerezPalacios, T. 2021. Evaluation of fresh meat quality by hyperspectral imaging (HSI), nuclear magnetic resonance (NMR) and magnetic resonance imaging (MRI): a review. Meat Science 172: 108340.

Antonelo, D.S., Cônsolo, N.R.B., Gómez, J.F.M., Beline, M., Goulart, R.S., Corte, R.R.P.S., Colnago, L.A., Schilling, M.W., Gerrard, D.E. and Silva, S.L. 2020. Metabolite profile and consumer sensory acceptability of meat from lean Nellore and Angus $\times$ Nellore crossbreed cattle fed soybean oil. Food Research International 132: 109056.

Arthur, T.M., Kalchayanand, N., Agga, G.E., Wheeler, T.L. and Koohmaraie, M. 2017. Evaluation of bacteriophage application to cattle in lairage at beef processing plants to reduce escherichia coli 0157:H7 prevalence on hides and carcasses. Foodborne Pathogens and Disease 14: 17-22.

Bazile, J., Picard, B., Chambon, C., Valais, A. and Bonnet, M. 2019. Pathways and biomarkers of marbling and carcass fat deposition in bovine revealed by a combination of gel-based and gel-free proteomic analyses. Meat Science 156: 146-155.

Bedhane, M., van der Werf, J., Gondro, C., Duijvesteijn, N., Lim, D., Park, B., Park, M.N., Hee, R.S. and Clark, S. 2019. Genome-wide association study of meat quality traits in hanwoo beef cattle using imputed whole-genome sequence data. Frontiers in Genetics 10: 1235.

Bekhit, A.E.D.A., Carne, A., Ha, M. and Franks, P. 2014. Physical interventions to manipulate texture and tenderness of fresh meat: a review. International Journal of Food Properties 17: 433-453.

Bendixen, E. 2013. "Proteomics in Foods" (eds. F. Toldrá and L.M.L. Nollet), Springer, USA, pages 3-19.

Bergholz, T.M., Moreno Switt, A.I. and Wiedmann, M. 2014. Omics approaches in food safety: fulfilling the promise? Trends in Microbiology 22: 275-281.

Berry, D.P., Conroy, S., Hegarty, P.J., Evans, R.D., Pabiou, T. and Judge, M.M. 2021. Inter-animal genetic variability exist in organoleptic properties of prime beef meat. Meat Science 173: 108401.

Beyts, C., Chaya, C., Dehrmann, F., James, S., Smart, K. and Hort, J. 2017. A comparison of self-reported emotional and implicit responses to aromas in beer. Food Quality and Preference 59: 68-80.

Bhat, Z.F., Morton, J.D., Mason, S.L. and Bekhit, A.E.D.A. 2018. Applied and emerging methods for meat tenderization: a comparative perspective. Comprehensive Reviews in Food Science and Food Safety 17: 841-859.

Bhat, Z.F., Morton, J.D., Mason, S.L. and Bekhit, A.E.D.A. 2019. Current and future prospects for the use of pulsed electric field in the meat industry. Critical Reviews in Food Science and Nutrition 59: 1660-1674.

Bhat, Z.F., Morton, J.D., Bekhit, A.E.D.A., Kumar, S. and Bhat, H.F. 2021. Emerging processing technologies for improved digestibility of muscle proteins. Trends in Food Science \& Technology 110: 226-239.

Bickhart, D.M., Rosen, B.D., Koren, S., Sayre, B.L., Hastie, A.R., Chan, S., Lee, J., Lam, E.T., Liachko, I., Sullivan, S.T., Burton, J.N., Huson, H.J., Nystrom, J.C., Kelley, C.M., Hutchison, J.L., Zhou, Y., Sun, J., Crisà, A., Ponce de León, F.A., Schwartz, J.C., Hammond, J.A., Waldbieser, G.C., Schroeder, S.G., Liu, G.E., Dunham, M.J., Shendure, J., Sonstegard, T.S., Phillippy, A.M., Van Tassell, C.P. and Smith, T.P.L. 2017. Single-molecule sequencing and chromatin conformation capture enable de novo reference assembly of the domestic goat genome. Nature Genetics 49: 643-650.

Bieche-Terrier, C., Auvray, F., Um, M.M., Allais, L. and Drouet, M. 2019. Prevalence of fecal carriage of main enterohemorrhagic Escherichia coli serotypes among slaughtered dairy calves in France. In: 65. International Congress of Meat Science and Technology (ICoMST 2019).

Bolormaa, S., Neto, L.R.P., Zhang, Y.D., Bunch, R.J., Harrison, B.E., Goddard, M.E. and Barendse. W. 2011. A genome-wide association study of meat and carcass traits in Australian cattle1. Journal of Animal Science 89: 2297-2309.

Bolumar, T., Orlien, V., Sikes, A., Aganovic, K., Bak, K.H., Guyon, C., Stübler, A.S., de Lamballerie, M., Hertel, C. and Brüggemann, D.A. 2021. High-pressure processing of meat: molecular impacts and industrial applications. Comprehensive Reviews in Food Science and Food Safety 20: 332-368.

Bordbar, F., Jensen, J., Du, M., Abied, A., Guo, W., Xu, L., Gao, $\mathrm{H}$., Zhang, L. and Li, J. 2020. Identification and validation of a novel candidate gene regulating net meat weight in Simmental beef cattle based on imputed next-generation sequencing. Cell Proliferation 53: e12870.

Borgogno, M., Cardello, A.V., Favotto, S. and Piasentier, E. 2017. An emotional approach to beef evaluation. Meat science 127: 1-5.

Bosilevac, J.M., Nou, X., Barkocy-Gallagher, G.A., Arthur, T.M. and Koohmaraie, M. 2006. Treatments using hot water instead of lactic acid reduce levels of aerobic bacteria and enterobacteriaceae and reduce the prevalence of Escherichia coli $0157: \mathrm{H} 7$ on preevisceration beef carcasses. Journal of Food Protection 69: 1808-1813.

Botinestean, C., Hossain, M., Mullen, A.M., Kerry, J.P. and Hamill, R.M. 2021. The influence of the interaction of sous-vide cooking time and papain concentration on tenderness and technological characteristics of meat products. Meat Science 177: 108491.

Botta, C., Ferrocino, I., Pessione, A., Cocolin, L., Rantsiou, K. and Elkins Christopher, A. 2020. Spatiotemporal distribution of the environmental microbiota in food processing plants as impacted by cleaning and sanitizing procedures: the case of slaughterhouses and gaseous ozone. Applied and Environmental Microbiology 86: e01861-e01820.

Brown, E., Dessai, U., McGarry, S. and Gerner-Smidt, P. 2019. Use of whole-genome sequencing for food safety and public health in the United States. Foodborne Pathogens and Disease 16: 441-450. 
Bruscadin, J.J., de Souza, M.M., de Oliveira, K.S., Rocha, M.I.P., Afonso, J., Cardoso, T.F., Zerlotini, A., Coutinho, L.L., Niciura, S.C.M. and de Almeida Regitano, L.C. 2021. Muscle allele-specific expression QTLs may affect meat quality traits in Bos indicus. Scientific Reports 11: 7321.

Buncic, S., Nychas, G.J., Lee, M.R.F., Koutsoumanis, K., Hébraud, M., Desvaux, M., Chorianopoulos, N., Bolton, D., Blagojevic, B. and Antic, D. 2014. Microbial pathogen control in the beef chain: recent research advances. Meat Science 97: 288-297.

Cafferky, J., Sweeney, T., Allen, P., Sahar, A., Downey, G., Cromie, A.R. and Hamill, R.M. 2020. Investigating the use of visible and near infrared spectroscopy to predict sensory and texture attributes of beef $\mathrm{M}$. longissimus thoracis et lumborum. Meat science 159: 107915.

Cama-Moncunill, R., Cafferky, J., Augier, C., Sweeney, T., Allen, P., Ferragina, A., Sullivan, C., Cromie, A. and Hamill, R.M. 2020. Prediction of warner-bratzler shear force, intramuscular fat, drip-loss and cook-loss in beef via Raman spectroscopy and chemometrics. Meat Science 167: 108157.

Cardoso, T.F., Coutinho, L.L., Bruscadin, J.J., Diniz, W.J.D.S., Petrini, J., Andrade, B.G.N., de Oliveira, P.S.N., Poleti, M.D., Cesar, A.S.M., Silveira, J.C.D., Chiaratti, M.R., Neto, A.Z., Mourão, G.B. and Regitano, L.C.A. 2021. Multi-omics approach reveals mir-snps affecting muscle fatty acids profile in nelore cattle. Genes 12: 1-18.

Casas, E., White, S., Wheeler, T.L., Shackelford, S.D., Koohmaraie, M., Riley, D., Chase, Jr. C., Johnson, D. and Smith, T. 2006. Effects of calpastatin and mu-calpain markers in beef cattle on tenderness traits. Journal of Animal Science 84: 520-525.

Ceciliani, F., Lecchi, C., Bazile, J. and Bonnet, M. 2018. "Proteomics in Domestic Animals: From Farm to Systems Biology" (eds. A.M. de Almeida, D. Eckersall, I. Miller), Springer International Publishing, Cham, pages 233-254.

Chen, J., Gu, J., Zhang, R., Mao, Y. and Tian, S. 2019. Freshness evaluation of three kinds of meats based on the electronic nose. Sensors 19: 605.

Cheng, S., Wang, X., Wang, Q., Yang, L., Shi, J. and Zhang, Q. 2020. Comparative analysis of Longissimus dorsi tissue from two sheep groups identifies differentially expressed genes related to growth, development and meat quality. Genomics 112: 3322-3330.

Corcoran, L.C., Schlich, P., K.A.M., Moloney, A.P., Botinestean, C., Gallagher, E.G.O.S.M. and Crofton, E.C. 2020. Comparing consumer liking of beef steaks from three different feeding systems using sensory temporal liking and traditional liking methods. Proceedings of the 48th Annual Food Science and Technology Conference (University of Limerick and IFSTI).

Crofton, E., Murray, N. and Botinestean, C. 2021. Exploring the effects of immersive virtual reality environments on sensory perception of beef steaks and chocolate. Foods 10: 1154.

Crofton, E.C., Botinestean, C., Fenelon, M. and Gallagher, E. 2019. Potential applications for virtual and augmented reality technologies in sensory science. Innovative Food Science \& Emerging Technologies 56: 102178.
Da Silva Diniz, W.J. and Ward, A.K. 2021. 282 Multi-omics approaches to improve animal production. Journal of Animal Science 99: 20-21.

de Andrade, J.C., Nalério, E.S., Giongo, C., de Barcellos, M.D., Ares, G. and Deliza, R. 2018. Consumer sensory and hedonic perception of sheep meat coppa under blind and informed conditions. Meat Science 137: 201-210.

de Marchi, M. 2013. On-line prediction of beef quality traits using near infrared spectroscopy. Meat Science 94: 455-460.

de Souza, M.M., Zerlotini, A., Rocha, M.I.P., Bruscadin, J.J., da Silva Diniz, W.J., Cardoso, T.F., Cesar, A.S.M., Afonso, J., Andrade, B.G.N., de Alvarenga Mudadu, M., Mokry, F.B., Tizioto, P.C., de Oliveira, P.S.N., Niciura, S.C.M., Coutinho, L.L. and de Almeida Regitano, L.C. 2020. Allele-specific expression is widespread in Bos indicus muscle and affects meat quality candidate genes. Scientific Reports 10: 10204.

de Wijk, R.A., Kooijman, V., Verhoeven, R.H.G., Holthuysen, N.T.E. and de Graaf, C. 2012. Autonomic nervous system responses on and facial expressions to the sight, smell, and taste of liked and disliked foods. Food Quality and Preference 26: 196-203.

di Luca, A., Elia, G., Hamill, R. and Mullen, A.M. 2013. 2D DIGE proteomic analysis of early post mortem muscle exudate highlights the importance of the stress response for improved water-holding capacity of fresh pork meat. Proteomics 13: 1528-1544.

di Luca, A., Hamill, R.M., Mullen, A.M., Slavov, N. and Elia, G. 2016. Comparative proteomic profiling of divergent phenotypes for water holding capacity across the Post Mortem ageing period in porcine muscle exudate. PLoS One 11: e0150605.

Dixit, Y., Hitchman, S., Hicks, T.M., Lim, P., Wong, C.K., Holibar, L., Gordon, K.C., Loeffen, M., Farouk, M.M., Craigie, C.R. and Reis, M.M. 2021. Non-invasive spectroscopic and imaging systems for prediction of beef quality in a meat processing pilot plant. Meat Science 181: 108410.

Djekic, I., Lorenzo, J.M., Munekata, P.E.S., Gagaoua, M. and Tomasevic, I. 2021. Review on characteristics of trained sensory panels in food science. Journal of Texture Studies 52: 501-509.

Dorsa, W.J., Cutter, C.N. and Siragusa, G.R. 1996a. Effectiveness of a steam-vacuum sanitizer for reducing Escherichia coli O157:H7 inoculated to beef carcass surface tissue. Letters in Applied Microbiology 23: 61-63.

Dorsa, W.J., Cutter, C.N. and Siragusa, G.R. 1996b. Evaluation of six sampling methods for recovery of bacteria from beef carcass surfaces. Letters in Applied Microbiology 22: 39-41.

EIMasry, G., Sun, D.-W. and Allen, P. 2011. Non-destructive determination of water-holding capacity in fresh beef by using NIR hyperspectral imaging. Food Research International 44: 26242633.

EIMasry, G., Sun, D.-W. and Allen, P. 2012. Near-infrared hyperspectral imaging for predicting colour, $\mathrm{pH}$ and tenderness of fresh beef. Journal of Food Engineering 110: 127-140.

Estelles-Lopez, L., Ropodi, A., Pavlidis, D., Fotopoulou, J., Gkousari, C., Peyrodie, A., Panagou, E., Nychas, G.-J. and Mohareb, F. 2017. An automated ranking platform for machine learning regression 
models for meat spoilage prediction using multi-spectral imaging and metabolic profiling. Food Research International 99: 206-215.

Fagerlund, A., Langsrud, S., Møretrø, T. and Elkins, C.A. 2020. Indepth longitudinal study of listeria monocytogenes ST9 isolates from the meat processing industry: resolving diversity and transmission patterns using whole-genome sequencing. Applied and Environmental Microbiology 86: e00579-20.

Fernandes, R., Carey, C., Hynes, J. and Papkovsky, D. 2019. GreenLight $^{\mathrm{TM}}$ model 960. Journal of AOAC International 96: 369-385.

Flores, M. 2017. Chapter 13 - The Eating Quality of Meat: III-Flavor A2 - Toldrá, Fidel. In: "Lawrie's Meat Science", Eight Edition, Woodhead Publishing, Duxford, United Kingdom, pages 383-417.

Frank, D., Oytam, Y. and Hughes, J. 2017. Chapter 27 - Sensory Perceptions and New Consumer Attitudes to Meat. In: "New Aspects of Meat Quality", (ed. P.P. Purslow), Woodhead Publishing, Kidlington, United Kingdom, pages 667-698.

Fu, Y., Wang, L., Tang, Z., Yin, D., Xu, J., Fan, Y., Li, X., Zhao, S. and Liu, X. 2020. An integration analysis based on genomic, transcriptomic and QTX information reveals credible candidate genes for fat-related traits in pigs. Animal Genetics 51: 683-693.

Gagaoua, M. 2021. "Three Phase Partitioning”, (eds. M. Gupta and I. Roy), Elsevier, pages 79-110.

Gagaoua, M. and Picard, B. 2020. Current advances in meat nutritional, sensory and physical quality improvement. Foods 9: 321.

Gagaoua, M., Terlouw, E.M., Micol, D., Boudjellal, A., Hocquette, J.F. and Picard, B. 2015. Understanding early post-mortem biochemical processes underlying meat color and $\mathrm{pH}$ decline in the longissimus thoracis muscle of young blond d'Aquitaine bulls using protein biomarkers. J Agric Food Chem 63: 6799-6809.

Gagaoua, M., Bonnet, M., Ellies-Oury, M.P., De Koning, L. and Picard, B. 2018a. Reverse phase protein arrays for the identification/ validation of biomarkers of beef texture and their use for early classification of carcasses. Food Chemistry 250: 245-252.

Gagaoua, M., Monteils, V. and Picard, B. 2018b. Data from the farmgate-to-meat continuum including omics-based biomarkers to better understand the variability of beef tenderness: an integromics approach. J Agric Food Chem 66: 13552-13563.

Gagaoua, M., Picard, B., Soulat, J. and Monteils, V. 2018c. Clustering of sensory eating qualities of beef: consistencies and differences within carcass, muscle, animal characteristics and rearing factors. Livestock Science 214: 245-258.

Gagaoua, M., Monteils, V., Couvreur, S. and Picard, B. 2019a. Beef tenderness prediction by a combination of statistical methods: chemometrics and supervised learning to manage integrative farm-to-meat continuum data. Foods 8: 274.

Gagaoua, M., Monteils, V. and Picard, B. 2019b. Decision tree, a learning tool for the prediction of beef tenderness using rearing factors and carcass characteristics. Journal of the Science of Food and Agriculture 99: 1275-1283.

Gagaoua, M., Picard, B. and Monteils, V. 2019c. Assessment of cattle inter-individual cluster variability: the potential of continuum data from the farm-to-fork for ultimate beef tenderness management. $J$ Sci Food Agric 99: 4129-4141.

Gagaoua, M., Bonnet, M. and Picard, B. 2020a. Protein array-based approach to evaluate biomarkers of beef tenderness and marbling in cows: understanding of the underlying mechanisms and prediction. Foods 9: 1180.

Gagaoua, M., Hughes, J., Terlouw, E.M.C., Warner, R.D., Purslow, P.P., Lorenzo, J.M. and Picard, B. 2020b. Proteomic biomarkers of beef colour. Trends in Food Science \& Technology 101: 234-252.

Gagaoua, M., Dib, A.L., Lakhdara, N., Lamri, M., Botineştean, C. and Lorenzo, J.M. 2021a. Artificial meat tenderization using plant cysteine proteases. Current Opinion in Food Science 38: 177-188.

Gagaoua, M., Terlouw, E.M.C., Mullen, A.M., Franco, D., Warner, R.D., Lorenzo, J.M., Purslow, P.P., Gerrard, D., Hopkins, D.L., Troy, D. and Picard, B. 2021b. Molecular signatures of beef tenderness: underlying mechanisms based on integromics of protein biomarkers from multi-platform proteomics studies. Meat Science 172: 108311.

Gagaoua, M., Troy, D. and Mullen, A.M. 2021c. The extent and rate of the appearance of the major 110 and $30 \mathrm{kDa}$ proteolytic fragments during post-mortem aging of beef depend on the glycolysing rate of the muscle and aging time: an LC-MS/MS approach to decipher their proteome and associated pathways. Journal of Agricultural and Food Chemistry 69: 602-614.

Gagaoua, M., Warner, R.D., Purslow, P., Ramanathan, R., Mullen, A.M., López-Pedrouso, M., Franco, D., Lorenzo, J.M., Tomasevic, I., Picard, B., Troy, D. and Terlouw, E.M.C. 2021d. Dark-cutting beef: a brief review and an integromics meta-analysis at the proteome level to decipher the underlying pathways. Meat science 181: 108611

Ghosh, M., Sharma, N., Singh, A.K., Gera, M., Pulicherla, K.K. and Jeong, D.K. 2018. Transformation of animal genomics by nextgeneration sequencing technologies: a decade of challenges and their impact on genetic architecture. Critical Reviews in Biotechnology 38: 1157-1175.

Ghougal, K., Dib, A.L., Lakhdara, N., Lamri, M., Baghezza, S., Azizi, A., Merrad, R., Zouikri, A., Cheraitia, D., Trouni, M., Soualah, H., Moreno, E., Espigares, E. and Gagaoua, M. 2021. Risk factors related to bacterial contamination by Enterobacteriaceae and fecal coliforms and the prevalence of Salmonella spp. in Algerian farms, slaughterhouses and butcheries: a two-year follow-up study. AIMS Agriculture and Food 6: 768-785.

Goldansaz, S.A., Guo, A.C., Sajed, T., Steele, M.A., Plastow, G.S. and Wishart, D.S. 2017. Livestock metabolomics and the livestock metabolome: a systematic review. PLoS One 12: e0177675.

Gonzalez-Recio, O., Daetwyler, H.D., MacLeod, I.M., Pryce, J.E., Bowman, P.J., Hayes, B.J. and Goddard, M.E. 2015. Rare variants in transcript and potential regulatory regions explain a small percentage of the missing heritability of complex traits in Cattle. PLoS One 10: e0143945.

Gowen, A.A., Feng, Y., Gaston, E. and Valdramidis, V. 2015. Recent applications of hyperspectral imaging in microbiology. Talanta 137: 43-54. 
Guo, B. and Dalrymple, B.P. 2017. Chapter 11 - Transcriptomics of Meat Quality. In: "New Aspects of Meat Quality", (ed. P.P. Purslow), Woodhead Publishing, Kidlington, United Kingdom, pages 259-320.

$\mathrm{Ha}$, M. and Warner, R.D. 2021 "Innovative Food Processing Technologies," (ed K. Knoerzer and K. Muthukumarappan), Elsevier, Oxford, pages 412-425.

Ha, M., McGilchrist, P., Polkinghorne, R., Huynh, L., Galletly, J., Kobayashi, K., Nishimura, T., Bonney, S., Kelman, K.R. and Warner, R.D. 2019a. Effects of different ageing methods on colour, yield, oxidation and sensory qualities of Australian beef loins consumed in Australia and Japan. Food Research International 125: 108528.

Ha, Y., Hwang, I., Ba, H.V., Ryu, S., Kim, Y., Kang, S.M., Kim, J., Kim, Y. and Cho, S. 2019b. Effects of dry- and wet-ageing on flavor compounds and eating quality of low fat hanwoo beef muscles. Food Science of Animal Resources 39: 655-667.

Hafid, K., John, J., Sayah, T.M., Dominguez, R., Becila, S., Lamri, M., Dib, A.L., Lorenzo, J.M. and Gagaoua, M. 2020. One-step recovery of latex papain from Carica papaya using three phase partitioning and its use as milk-clotting and meat-tenderizing agent. International Journal of Biological Macromolecules 146: 798-810.

Hayes, B.J. and Daetwyler, H.D. 2019. 1000 bull genomes project to map simple and complex genetic traits in cattle: applications and outcomes. Annual Review of Animal Biosciences 7: 89-102.

Herrero, M., Simó, C., García-Cañas, V., Ibáñez, E. and Cifuentes, A. 2012. Foodomics: MS-based strategies in modern food science and nutrition. Mass Spectrometry Reviews 31: 49-69.

Hocquette, J.F., Botreau, R., Picard, B., Jacquet, A., Pethick, D.W. and Scollan, N.D. 2012. Opportunities for predicting and manipulating beef quality. Meat Science 92: 197-209.

Holman, B.W.B. and Hopkins, D.L. 2021. The use of conventional laboratory-based methods to predict consumer acceptance of beef and sheep meat: a review. Meat Science 181: 108586.

Hu, Z.-L., Park, C.A. and Reecy, J.M. 2018. Building a livestock genetic and genomic information knowledgebase through integrative developments of Animal QTLdb and CorrDB. Nucleic Acids Research 47: D701-D710.

Hultman, J., Johansson, P., Björkroth, J. and Drake, H.L. 2020. Longitudinal metatranscriptomic analysis of a meat spoilage microbiome detects abundant continued fermentation and environmental stress responses during shelf life and beyond. Applied and Environmental Microbiology 86: e01575-20.

Hwang, I.H., Devine, C.E. and Hopkins, D.L. 2003 The biochemical and physical effects of electrical stimulation on beef and sheep meat tenderness. Meat Science 65: 677-691.

Jagadeesan, B., Gerner-Smidt, P., Allard, M.W., Leuillet, S., Winkler, A., Xiao, Y., Chaffron, S., Van Der Vossen, J., Tang, S., Katase, M., McClure, P., Kimura, B., Ching Chai, L., Chapman, J. and Grant, K. 2019. The use of next generation sequencing for improving food safety: translation into practice. Food Microbiology 79: 96-115.
Jeong, J.Y., Baek, Y.-C., Ji, S.Y., Oh, Y.K., Cho, S., Seo, H.-W., Kim, M. and Lee, H.-J. 2020. Nuclear magnetic resonance-based metabolomics analysis and characteristics of beef in different fattening periods. Journal of Animal Science and Technology 62: 321-333.

Jung, Y., Lee, J., Kwon, J., Lee, K.-S., Ryu, D.H. and Hwang, G.S. 2010. Discrimination of the geographical origin of beef by $1 \mathrm{H}$ NMR-based metabolomics. Journal of Agricultural and Food Chemistry 58: 10458-10466.

Kalchayanand, N., Arthur, T.M., Bosilevac, J.M., Schmidt, J.W., Wang, R., Shackelford, S.D. and Wheeler, T.L. 2012. Evaluation of commonly used antimicrobial interventions for fresh beef inoculated with Shiga toxin-producing Escherichia coli serotypes O26, O45, O103, O111, 0121, 0145, and 0157: H7. Journal of Food Protection 75: 1207-1212.

Kamruzzaman, M., EIMasry, G., Sun, D.-W. and Allen, P. 2012. Nondestructive prediction and visualization of chemical composition in lamb meat using NIR hyperspectral imaging and multivariate regression. Innovative Food Science \& Emerging Technologies 16: 218-226.

Kamruzzaman, M., EIMasry, G., Sun, D.-W. and Allen, P. 2013. Nondestructive assessment of instrumental and sensory tenderness of lamb meat using NIR hyperspectral imaging. Food Chemistry 141: 389-396.

Kang, D., Zhang, W., Lorenzo, J.M. and Chen, X. 2021. Structural and functional modification of food proteins by high power ultrasound and its application in meat processing. Critical Reviews in Food Science and Nutrition 61: 1914-1933.

Kaur, M., Bowman, J.P., Porteus, B., Dann, A.L. and Tamplin, M. 2017. Effect of abattoir and cut on variations in microbial communities of vacuum-packaged beef. Meat Science 131: 34-39.

Killinger, K.M., Calkins, C.R., Umberger, W.J., Feuz, D.M. and Eskridge, K.M. 2004. Consumer sensory acceptance and value for beef steaks of similar tenderness, but differing in marbling level. Journal of Animal Science 82: 3294-3301.

Kim, Y.H.B., Ma, D., Setyabrata, D., Farouk, M.M., Lonergan, S.M., Huff-Lonergan, E. and Hunt, M.C. 2018. Understanding postmortem biochemical processes and post-harvest aging factors to develop novel smart-aging strategies. Meat Science 144: 74-90.

King, D.A., Shackelford, S.D., Broeckling, C.D., Prenni, J.E., Belk, K.E. and Wheeler, T.L. 2019. Metabolomic investigation of tenderness and aging response in beef longissimus steaks. Meat and Muscle Biology 3: 76.

Kodani, Y., Miyakawa, T., Komatsu, T. and Tanokura, M. 2017. NMRbased metabolomics for simultaneously evaluating multiple determinants of primary beef quality in Japanese Black cattle. Scientific Reports 7: 1297.

Kodogiannis, V.S. 2018 "A Rapid Detection of Meat Spoilage Using an Electronic Nose and Fuzzy-Wavelet Systems," Springer International Publishing, Cham, pages 521-539.

Konda Naganathan, G., Cluff, K., Samal, A., Calkins, C.R., Jones, D.D., Lorenzen, C.L. and Subbiah, J. 2015a. Hyperspectral 
imaging of ribeye muscle on hanging beef carcasses for tenderness assessment. Computers and Electronics in Agriculture 116: 55-64.

Konda Naganathan, G., Cluff, K., Samal, A., Calkins, C.R., Jones, D.D., Lorenzen, C.L. and Subbiah, J. 2015b. A prototype on-line AOTF hyperspectral image acquisition system for tenderness assessment of beef carcasses. Journal of Food Engineering 154: $1-9$.

Korsak, N., Taminiau, B., Hupperts, C., Delhalle, L., Nezer, C., Delcenserie, V. and Daube, G. 2017. Assessment of bacterial superficial contamination in classical or ritually slaughtered cattle using metagenetics and microbiological analysis. International Journal of Food Microbiology 247: 79-86.

Lamb, H.J., Hayes, B.J., Nguyen, L.T. and Ross, E.M. 2020. The future of livestock management: a review of real-time portable sequencing applied to livestock. Genes 11: 1-27.

Lawless, H.T. and Heymann, H. 2010. "Sensory Evaluation of Food: Principles and Practices". Springer, New York.

Leal-Gutiérrez, J.D., Elzo, M.A., Carr, C. and Mateescu, R.G. 2020a. RNA-seq analysis identifies cytoskeletal structural genes and pathways for meat quality in beef. PLoS One 15: e0240895.

Leal-Gutiérrez, J.D., Elzo, M.A. and Mateescu, R.G. 2020b. Identification of eQTLs and SQTLs associated with meat quality in beef. BMC Genomics 21: 104.

Leal-Gutiérrez, J.D., Rezende, F.M., Reecy, J.M., Kramer, L.M., Peñagaricano, F. and Mateescu, R.G. 2020c. Whole genome sequence data provides novel insights into the genetic architecture of meat quality traits in beef. Frontiers in Genetics 11: 538640.

López-Pedrouso, M., Lorenzo, J.M., Gagaoua, M. and Franco, D. 2020. Application of proteomic technologies to assess the quality of raw pork and pork products: an overview from farm-to-fork. Biology 9: 393.

Low, W.Y., Tearle, R., Bickhart, D.M., Rosen, B.D., Kingan, S.B., Swale, T., Thibaud-Nissen, F., Murphy, T.D., Young, R., Lefevre, L., Hume, D.A., Collins, A., Ajmone-Marsan, P., Smith, T.P.L. and Williams, J.L. 2019. Chromosome-level assembly of the water buffalo genome surpasses human and goat genomes in sequence contiguity. Nature Communications 10: 260.

Ma, D., Kim, Y.H.B., Cooper, B., Oh, J.-H., Chun, H., Choe, J.-H., Schoonmaker, J.P., Ajuwon, K. and Min, B. 2017. Metabolomics profiling to determine the effect of postmortem aging on color and lipid oxidative stabilities of different bovine muscles. Journal of Agricultural and Food Chemistry 65: 6708-6716.

Maher, S.C., Mullen, A.M., Moloney, A.P., Buckley, D.J. and Kerry, J.P. 2004. Quantifying the extent of variation in the eating quality traits of the $\mathrm{M}$. longissimus dorsi and $\mathrm{M}$. semimembranosus of conventionally processed Irish beef. Meat Science 66: 351-360.

Mamani-Linares, L.W., Gallo, C. and Alomar, D. 2012. Identification of cattle, llama and horse meat by near infrared reflectance or transflectance spectroscopy. Meat Science 90: 378-385.

Man, K.-Y., Chan, C.-O., Tang, H.-H., Dong, N.-P., Capozzi, F., Wong, K.-H., Kwok, K.W.W., Chan, H.M. and Mok, D.K.-W. 2021.
Mass spectrometry-based untargeted metabolomics approach for differentiation of beef of different geographic origins. Food Chemistry 338: 127847.

Mansur, A.R., Song, E.-J., Cho, Y.-S., Nam, Y.-D., Choi, Y.-S., Kim, D.-O., Seo, D.-H. and Nam, T.G. 2019. Comparative evaluation of spoilage-related bacterial diversity and metabolite profiles in chilled beef stored under air and vacuum packaging. Food Microbiology 77: 166-172.

McClure, M.C., Ramey, H.R., Rolf, M.M., McKay, S.D., Decker, J.E., Chapple, R.H., Kim, J.W., Taxis, T.M., Weaber, R.L., Schnabel, R.D. and Taylor, J.F. 2012. Genome-wide association analysis for quantitative trait loci influencing Warner-Bratzler shear force in five taurine cattle breeds. Animal Genetics 43: 662-673.

McDonnell, C.K., Fitzgerald, A.G., Burt, P., Hughes, J., Mellor, G.E., Barlow, R.S., Sikes, A.L., Li, Y. and Tobin, A.B. 2021. The effect of electro-hydrodynamic shockwaves on the quality of striploin and brisket beef muscles during long-term storage. Innovative Food Science \& Emerging Technologies 68: 102627.

Meuwissen, T., Hayes, B. and Goddard, M. 2016. Genomic selection: a paradigm shift in animal breeding. Animal Frontiers 6: 6-14.

Miller, R. 2020. Drivers of consumer liking for beef, pork, and lamb: a review. Foods 9: 428.

Mills, J., Donnison, A. and Brightwell, G. 2014. Factors affecting microbial spoilage and shelf-life of chilled vacuum-packed lamb transported to distant markets: a review. Meat science 98: 71-80.

Moloney, A.P., Mooney, M.T., Kerry, J.P. and Troy, D.J. 2001. Producing tender and flavoursome beef with enhanced nutritional characteristics. Proceedings of the Nutrition Society 60: 221-229.

Moran, L., Andres, S., Allen, P. and Moloney, A.P. 2018. Visible and near infrared spectroscopy as an authentication tool: preliminary investigation of the prediction of the ageing time of beef steaks. Meat science 142: 52-58.

Munekata, P.E.E., Pateiro, M., López-Pedrouso, M., Gagaoua, M. and Lorenzo, J.M. 2021. Foodomics in meat quality. Current Opinion in Food Science 38: 79-85.

Mungure, T.E., Farouk, M.M., Birch, E.J., Carne, A., Staincliffe, M., Stewart, I. and Bekhit, A.E.-D.A. 2020. Effect of PEF treatment on meat quality attributes, ultrastructure and metabolite profiles of wet and dry aged venison Longissimus dorsi muscle. Innovative Food Science \& Emerging Technologies 65: 102457.

Muroya, S., Ueda, S., Komatsu, T., Miyakawa, T. and Ertbjerg, P. 2020. MEATabolomics: muscle and meat metabolomics in domestic animals. Metabolites 10: 188.

Nair, M.N., Li, S., Beach, C., Rentfrow, G. and Suman, S.P. 2018a. Intramuscular variations in color and sarcoplasmic proteome of beef semimembranosus during postmortem aging. Meat and Muscle Biology 2: 92-101.

Nair, M.N., Li, S., Beach, C.M., Rentfrow, G. and Suman, S.P. 2018b. Changes in the sarcoplasmic proteome of beef muscles with differential color stability during postmortem aging. Meat and Muscle Biology 2: 1-17. 
Nair, M.N., Canto, A.C.V.C.S., Rentfrow, G. and Suman, S.P. 2019. Muscle-specific effect of aging on beef tenderness. LWT 100: 250-252.

Nicolaï, B.M., Beullens, K., Bobelyn, E., Peirs, A., Saeys, W., Theron, K.I. and Lammertyn, J. 2007. Nondestructive measurement of fruit and vegetable quality by means of NIR spectroscopy: a review. Postharvest Biology and Technology 46: 99-118.

O'Doherty, A.M., MacHugh, D.E., Spillane, C. and Magee, D.A. 2015. Genomic imprinting effects on complex traits in domesticated animal species. Frontiers in Genetics 6: 156.

O'Quinn, T.G., Legako, J.F., Brooks, J.C. and Miller, M.F. 2018. Evaluation of the contribution of tenderness, juiciness, and flavor to the overall consumer beef eating experience1. Translational Animal Science 2: 26-36.

Osorio, M.T., Moloney, A.P., Brennan, L. and Monahan, F.J. 2012. Authentication of beef production systems using a metabolomicbased approach. Animal 6: 167-172.

Ouali, A., Gagaoua, M., Boudida, Y., Becila, S., Boudjellal, A., HerreraMendez, C.H. and Sentandreu, M.A. 2013. Biomarkers of meat tenderness: present knowledge and perspectives in regards to our current understanding of the mechanisms involved. Meat science 95: 854-870.

Page, B.T., Casas, E., Heaton, M.P., Cullen, N.G., Hyndman, D.L., Morris, C.A., Crawford, A.M., Wheeler, T.L., Koohmaraie, M., Keele, J.W. and Smith, T.P.P. 2002. Evaluation of single-nucleotide polymorphisms in CAPN1 for association with meat tenderness in cattle. Journal of Animal Science 80: 3077-3085.

Panagou, E.Z., Papadopoulou, O., Carstensen, J.M. and Nychas, G.J.E. 2014. Potential of multispectral imaging technology for rapid and non-destructive determination of the microbiological quality of beef filets during aerobic storage. International Journal of Food Microbiology 174: 1-11.

Picard, B. and Gagaoua, M. 2017. "Proteomics in Food Science: From Farm to Fork," (ed. M.L. Colgrave), Academic Press, London, pages 177-197.

Picard, B. and Gagaoua, M. 2020. Meta-proteomics for the discovery of protein biomarkers of beef tenderness: an overview of integrated studies. Food Res Int 127: 108739.

Picard, B., Gagaoua, M. and Hollung, K. 2017. "New Aspects of Meat Quality: From Genes to Ethics," (ed. P. Purslow), Woodhead Publishing, UK, pages 321-354.

Pintado, A.I.I., Monteiro, M.J.J., Talon, R., Leroy, S., Scislowski, V., Fliedel, G., Rakoto, D., Maraval, I., Costa, A.I.I., Silva, A.P., Pallet, D., Tomlins, K. and Pintado, M.M.M. 2016. Consumer acceptance and sensory profiling of reengineered kitoza products. Food Chemistry 198: 75-84.

Poirier, S., Rué, O., Peguilhan, R., Coeuret, G., Zagorec, M., Champomier-Vergès, M.-C., Loux, V. and Chaillou, S. 2018. Deciphering intra-species bacterial diversity of meat and seafood spoilage microbiota using gyrB amplicon sequencing: a comparative analysis with $16 \mathrm{~S}$ rDNA V3-V4 amplicon sequencing. PLoS One 13: e0204629.
Poleti, M.D., Moncau, C.T., Silva-Vignato, B., Rosa, A.F., Lobo, A.R., Cataldi, T.R., Negrao, J.A., Silva, S.L., Eler, J.P. and de Carvalho Balieiro, J.C. 2018. Label-free quantitative proteomic analysis reveals muscle contraction and metabolism proteins linked to ultimate $\mathrm{pH}$ in bovine skeletal muscle. Meat science 145: 209-219.

Polkinghorne, R. 2018. From commodity, to customer, to consumer: the Australian beef industry evolution. Animal Frontiers 8: 47-52.

Prieto, N., Pawluczyk, O., Dugan, M.E.E. and Aalhus, J.L. 2017. A review of the principles and applications of near-infrared spectroscopy to characterize meat, fat, and meat products. Applied Spectroscopy 71: 1403-1426.

Purslow, P.P., Gagaoua, M. and Warner, R.D. 2021. Insights on meat quality from combining traditional studies and proteomics. Meat science 174: 108423.

Ramanathan, R., Mafi, G.G., Yoder, L., Perry, M., Pfeiffer, M., VanOverbeke, D.L. and Maheswarappa, N.B. 2020. Chapter 5 Biochemical changes of postmortem meat during the aging process and strategies to improve the meat quality. In: "Meat Quality Analysis", (eds. A.K. Biswas and P.K. Mandal), Academic Press, London, United Kingdom, pages 67-80.

Ransom, J., Belk, K., Sofos, J., Stopforth, J., Scanga, J. and Smith, G. 2003. Comparison of intervention technologies for reducing Escherichia coli 0157: H7 on beef cuts and trimmings. Food Protection Trends 23: 24-34.

Ross, C.F. 2021. Considerations of the use of the electronic tongue in sensory science. Current Opinion in Food Science 40: 87-93.

Ruiz-Capillas, C., Herrero, A.M., Pintado, T. and Delgado-Pando, G. 2021. sensory analysis and consumer research in new meat products development. Foods 10: 429.

Santos, D.I., Fraqueza, M.J., Pissarra, H., Saraiva, J.A., Vicente, A.A. and Moldão-Martins, M. 2020. Optimization of the effect of pineapple by-products enhanced in bromelain by hydrostatic pressure on the texture and overall quality of silverside beef cut. Foods 9: 1752.

Savoia, S., Albera, A., Brugiapaglia, A., Di Stasio, L., Ferragina, A., Cecchinato, A. and Bittante, G. 2020. Prediction of meat quality traits in the abattoir using portable and hand-held near-infrared spectrometers. Meat science 161: 108017.

Siegrist, M., Ung, C.-Y., Zank, M., Marinello, M., Kunz, A., Hartmann, C. and Menozzi, M. 2019. Consumers' food selection behaviors in three-dimensional (3D) virtual reality. Food Research International 117: 50-59.

Sikes, A.L. and Warner, R. 2016. 10 - Application of High Hydrostatic Pressure for Meat Tenderization. In: "Innovative Food Processing Technologies", Woodhead Publishing, Duxford, United Kingdom, pages 259-290.

Stellato, G., La Storia, A., De Filippis, F., Borriello, G., Villani, F., Ercolini, D. and Elkins, C.A. 2016. Overlap of spoilage-associated microbiota between meat and the meat processing environment in small-scale and large-scale retail distributions. Applied and Environmental Microbiology 82: 4045-4054. 
Suwandy, V., Carne, A., van de Ven, R., Bekhit, A.E.-D.A. and Hopkins, D.L. 2015a. Effect of pulsed electric field treatment on hot-boned muscles of different potential tenderness. Meat science 105: 25-31.

Suwandy, V., Carne, A., van de Ven, R., Bekhit, A.E.D.A. and Hopkins, D.L. 2015b. Effect of pulsed electric field treatment on the eating and keeping qualities of cold-boned beef loins: impact of initial ph and fibre orientation. Food and Bioprocess Technology 8: 1355-1365.

Tait-Burkard, C., Doeschl-Wilson, A., McGrew, M.J., Archibald, A.L., Sang, H.M., Houston, R.D., Whitelaw, C.B. and Watson, M. 2018. Livestock 2.0 - Genome editing for fitter, healthier, and more productive farmed animals. Genome Biology 19: 204.

Tan, J. and Xu, J. 2020. Applications of electronic nose (e-nose) and electronic tongue (e-tongue) in food quality-related properties determination: a review. Artificial Intelligence in Agriculture 4: 104-115.

Tao, F., Peng, Y., Gomes, C.L., Chao, K. and Qin, J. 2015. A comparative study for improving prediction of total viable count in beef based on hyperspectral scattering characteristics. Journal of Food Engineering 162: 38-47.

Tao, Y., Ma, L., Li, D., Tian, Y., Liu, J. and Liu, D. 2021. Proteomics analysis to investigate the effect of oxidized protein on meat color and water holding capacity in Tan mutton under low temperature storage. LWT 146: 111429.

Tapp, W.N., Davis, T.H., Paniukov, D., Brooks, J.C., Brashears, M.M. and Miller, M.F. 2017. Beef assessments using functional magnetic resonance imaging and sensory evaluation. Meat science 126: 11-17.

Taylor, J.F., Whitacre, L.K., Hoff, J.L., Tizioto, P.C., Kim, J., Decker, J.E. and Schnabel, R.D. 2016. Lessons for livestock genomics from genome and transcriptome sequencing in cattle and other mammals. Genetics Selection Evolution 48: 59.

Terlouw, E.M.M., Picard, B., Deiss, V., Berri, C., Hocquette, J.-F., Lebret, B., Lefèvre, F., Hamill, R. and Gagaoua, M. 2021. Understanding the determination of meat quality using biochemical characteristics of the muscle: stress at slaughter and other missing keys. Foods 10: 84.

Troy, D.J. and Kerry, J.P. 2010. Consumer perception and the role of science in the meat industry. Meat science 86: 214-226.

Van Laere, A., Nguyen, M., Braunschwieg, M., Nezer, C., Collette, C., Moreau, L., Archibald, A.L., Haley, C.S., Buys, N., Tally, M., Andersson, G., Georges, M. and Andersson, L. 2003. A regulatory mutation in IGF2 causes a major QTL effect on muscle growth in the pig. Nature 425: 832-835.

Viemose, I., Møller, P., Laugesen, J.L., Schachtman, T.R., Manoharan, T. and Christoffersen, G.R.R. 2013. Appetitive long-term taste conditioning enhances human visually evoked EEG responses. Behavioural Brain Research 253: 1-8.

Wang, T., Zhao, L., Sun, Y., Ren, F., Chen, S., Zhang, H. and Guo, H. 2016. Changes in the microbiota of lamb packaged in a vacuum and in modified atmospheres during chilled storage analysed by high-throughput sequencing. Meat science 121: 253-260.
Wang, K., Pu, H. and Sun, D.-W. 2018. Emerging spectroscopic and spectral imaging techniques for the rapid detection of microorganisms: an overview. Comprehensive Reviews in Food Science and Food Safety 17: 256-273.

Wang, B., Wang, Y., Zuo, S., Peng, S., Wang, Z., Zhang, Y. and Luo, H. 2021. Untargeted and targeted metabolomics profiling of muscle reveals enhanced meat quality in artificial pasture grazing tan lambs via rescheduling the rumen bacterial community. Journal of Agricultural and Food Chemistry 69: 846-858.

Warner, R.D., McDonnell, C.K., Bekhit, A.E.E., Claus, J., Vaskoska, R., Sikes, A., Dunshea, F.R. and Ha, M. 2017. Systematic review of emerging and innovative technologies for meat tenderisation. Meat science 132: 72-89.

Warner, R., Miller, R., Ha, M., Wheeler, T.L., Dunshea, F., Li, X., Vaskoska, R., Purslow, P. and Wheeler, T. 2021. Meat tenderness: underlying mechanisms, instrumental measurement, and sensory assessment. Meat and Muscle Biology 4: 1-25.

Watanabe, G., Motoyama, M., Orita, K., Takita, K., Aonuma, T., Nakajima, I., Tajima, A., Abe, A. and Sasaki, K. 2019. Assessment of the dynamics of sensory perception of Wagyu beef strip loin prepared with different cooking methods and fattening periods using the temporal dominance of sensations. Food Science \& Nutrition 7: 3538-3548.

Watson, R., Gee, A., Polkinghorne, R. and Porter, M. 2008a. Consumer assessment of eating quality development of protocols for Meat Standards Australia (MSA) testing. Australian Journal of Experimental Agriculture 48: 1360-1367.

Watson, R., Polkinghorne, R. and Thompson, J.M. $2008 \mathrm{~b}$. Development of the Meat Standards Australia (MSA) prediction model for beef palatability. Australian Journal of Experimental Agriculture 48: 1368-1379.

Weeranantanaphan, J., Downey, G., Allen, P. and Sun, D.-W. 2011. A review of near infrared spectroscopy in muscle food analysis: 2005-2010. Journal of Near Infrared Spectroscopy 19: 61-104.

Welzenbach, J., Neuhoff, C., Heidt, H., Cinar, M.U., Looft, C., Schellander, K., Tholen, E. and Große-Brinkhaus, C. 2016. Integrative analysis of metabolomic, proteomic and genomic data to reveal functional pathways and candidate genes for drip loss in pigs. International Journal of Molecular Sciences 17: 1426.

Wheeler, T.L., Kalchayanand, N. and Bosilevac, J.M. 2014. Pre- and post-harvest interventions to reduce pathogen contamination in the U.S. beef industry. Meat science 98: 372-382.

Xia, J., Qi, X., Wu, Y., Zhu, B., Xu, L., Zhang, L., Gao, X., Chen, Y., $\mathrm{Li}, \mathrm{J}$. and Gao, H. 2016. Genome-wide association study identifies loci and candidate genes for meat quality traits in Simmental beef cattle. Mammalian Genome 27: 246-255.

Yang, X., Noyes, N.R., Doster, E., Martin, J.N., Linke, L.M., Magnuson, R.J., Yang, H., Geornaras, I., Woerner, D.R., Jones, K.L., Ruiz, J., Boucher, C., Morley, P.S., Belk, K.E. and Dozois, C.M. 2016. Use of metagenomic shotgun sequencing technology to detect foodborne pathogens within the microbiome of the beef 
production chain. Applied and environmental microbiology $\mathbf{8 2}$ : 2433-2443.

Zhilyaev, S., Cadavez, V., Gonzales-Barron, U., Phetxumphou, K. and Gallagher, D. 2017. Meta-analysis on the effect of interventions used in cattle processing plants to reduce Escherichia coli contamination. Food Research International 93: 16-25.

Zhou, C.-Y., Pan, D.-D., Cao, J.-X. and Zhou, G.-H. 2021. A comprehensive review on molecular mechanism of defective drycured ham with excessive pastiness, adhesiveness, and bitterness by proteomics insights. Comprehensive Reviews in Food Science and Food Safety 20: 3838-3857.

Zhu, C., Petracci, M., Li, C., Fiore, E. and Laghi, L. 2020. An untargeted metabolomics investigation of Jiulong Yak (Bos grunniens) meat by 1H-NMR. Foods 9: 481 .
Zhu, Y., Gagaoua, M., Mullen, A.M., Kelly, A.L., Sweeney, T., Cafferky, J., Viala, D. and Hamill, R.M. 2021a. A proteomic study for the discovery of beef tenderness biomarkers and prediction of Warner-Bratzler shear force measured on longissimus thoracis muscles of young limousin-sired bulls. Foods 10: 952.

Zhu, Y., Gagaoua, M., Mullen, A.M., Viala, D., Rai, D.K., Kelly, A.L., Sheehan, D. and Hamill, R.M. 2021b. Shotgun proteomics for the preliminary identification of biomarkers of beef sensory tenderness, juiciness and chewiness from plasma and muscle of young Limousin-sired bulls. Meat science 176: 108488.

Zuckerman, H., Bowker, B.C., Eastridge, J.S. and Solomon, M.B. 2013. Microstructure alterations in beef intramuscular connective tissue caused by hydrodynamic pressure processing. Meat science 95: 603-607. 